OPEN ACCESS

Edited by:

Eric T. Harvill,

University of Georgia, United States

Reviewed by:

Anwa Kurabi,

University of California, San Diego,

United States

Lauren O. Bakaletz,

Nationwide Children's Hospital,

United States

Anke Leichtle,

University of Lübeck, Germany

*Correspondence:

Kirsten M. Spann

Kirsten.Spann@qut.edu.au

${ }^{t}$ These authors share first authorship

Specialty section:

This article was submitted to

Bacteria and Host,

a section of the journal

Frontiers in Cellular and

Infection Microbiology

Received: 26 August 2021

Accepted: 11 October 2021

Published: 29 October 2021

Citation:

Massa HM, Spann KM and

Cripps AW (2021) Innate Immunity

in the Middle Ear Mucosa.

Front. Cell. Infect. Microbiol. 11:764772.

doi: 10.3389/fcimb.2021.764772

\section{Innate Immunity in the Middle Ear Mucosa}

\author{
Helen M. Massa ${ }^{1 \dagger}$, Kirsten M. Spann ${ }^{2 \star t}$ and Allan W. Cripps ${ }^{3,4}$ \\ ${ }^{1}$ School of Pharmacy and Medical Science, Griffith University, Gold Coast, QLD, Australia, ${ }^{2}$ Centre for Immunology and \\ Infection Control, School of Biomedical Sciences, Queensland University of Technology, Brisbane, QLD, Australia, ${ }^{3}$ Menzies \\ Health Institute Queensland, School of Medicine, Griffith University, Gold Coast, QLD, Australia, ${ }^{4}$ School of Medicine and \\ Dentistry, Griffith University, Gold Coast, QLD, Australia
}

Otitis media $(\mathrm{OM})$ encompasses a spectrum of clinical presentations ranging from the readily identifiable Acute $\mathrm{OM}(\mathrm{AOM})$, which is characterised by otalgia and fever, to chronic otitis media with effusion (COME) where impaired hearing due to middle ear effusion may be the only clinical symptom. Chronic suppurative OM (CSOM) presents as a more severe form of $\mathrm{OM}$, involving perforation of the tympanic membrane. The pathogenesis of OM in these varied clinical presentations is unclear but activation of the innate inflammatory responses to viral and/or bacterial infection of the upper respiratory tract performs an integral role. This localised inflammatory response can persist even after pathogens are cleared from the middle ear, eustachian tubes and, in the case of respiratory viruses, even the nasal compartment. Children prone to OM may experience an over exuberant inflammatory response that underlies the development of chronic forms of $\mathrm{OM}$ and their sequelae, including hearing impairment. Treatments for chronic effusive forms of $\mathrm{OM}$ are limited, with current therapeutic guidelines recommending a "watch and wait" strategy rather than active treatment with antibiotics, corticosteroids or other anti-inflammatory drugs. Overall, there is a clear need for more targeted and effective treatments that either prevent or reduce the hyper-inflammatory response associated with chronic forms of OM. Improved treatment options rely upon an in-depth understanding of OM pathogenesis, particularly the role of the host innate immune response during acute OM. In this paper, we review the current literature regarding the innate immune response within the middle ear to bacterial and viral otopathogens alone, and as co-infections. This is an important consideration, as the role of respiratory viruses as primary pathogens in $\mathrm{OM}$ is not yet fully understood. Furthermore, increased reporting from PCR-based diagnostics, indicates that viral/bacterial co-infections in the middle ear are more common than bacterial infections alone. Increasingly, the mechanisms by which viral/bacterial coinfections may drive or maintain complex innate immune responses and inflammation during $\mathrm{OM}$ as a chronic response require investigation. Improved understanding of the pathogenesis of chronic OM, including host innate immune response within the middle ear is vital for development of improved diagnostic and treatment options for our children.

Keywords: innate immunity, otitis media, non-typeable Haemophilus influenzae, influenza A virus, otopathogens, bacteria, viruses, mucosa 


\section{INTRODUCTION}

Otitis media $(\mathrm{OM})$ is defined as inflammation of the middle ear and encompasses a range of clinical presentations. Acute OM $(\mathrm{AOM})$ is characterised by otalgia and fever and may occur occasionally, particularly during a child's first 3 years of life. If acute episodes occur a minimum of 3 times in a 6 month period or more than 4 times within a 12 month period the condition is considered to be recurrent (RAOM) (Granath, 2017). Otitis media with effusion (OME) is defined by the presence of middle ear fluid, or effusion, without any symptoms except impaired hearing due to restricted mobility of the tympanic membrane. Chronic suppurative OM (CSOM) involves perforation of the tympanic membrane with persistent fluid discharge for more than 6 weeks (Kong and Coates, 2009; Lieberthal et al., 2013; Massa et al., 2015; Bhutta et al., 2017).

The pathogenesis of $\mathrm{OM}$ is largely due to activation of the innate inflammatory responses to viral and/or bacterial infection of the upper respiratory tract (Mandel et al. 2008; Bakaletz, 2010; Mittal et al., 2014a; Parrish et al., 2019). Pathogen-induced inflammation in the nasopharynx (primarily due to viral infections) and eustachian tubes (both viral and bacterial infections) then leads to a range of responses including enhanced mucus secretion (Val et al., 2018), neutrophil extracellular traps (Thornton et al., 2013), damage to the epithelium and enhanced commensal bacterial colonisation (Nokso-Koivisto et al., 2015; Chonmaitree et al., 2016). Nasopharyngeal inflammation also causes a loss of pressure equilibrium with the middle ear (Martin et al., 2017), allowing fluid accumulation and invasion of viruses and commensal bacteria. Unresolved inflammation then leads to the reoccurring or chronic infections and fluid build-up in the middle ear that are the hallmarks of recurrent and chronic forms of OM (Bhutta et al., 2017).

In most children, $\mathrm{AOM}$ is resolved by the mucosal immune response of the middle ear and upper respiratory tract, that protects against repeated infections of the middle ear during the early years of development when children are at highest risk for ear disease. Progressively, the mean frequency of AOM episodes experienced by a child falls from 1.97 per year at six months of age to 1.07 per year by 36 months of age (Chonmaitree et al., 2008). Although overall, by three years of age, $60 \%$ of children have experienced one or more episodes of OM and $24 \%$ have experienced three or more episodes (Kaur et al., 2017). However, the global burden of disease caused by recurrent and chronic forms of OM, that are not as well controlled by the immune system, is considerable, particularly during the first 5 years of life. Globally, CSOM occurs in $4.76 \%$ of the population $(22 \%$ in children under 5 years old) with hearing impairment present in 30 children per 10,000 (Monasta et al., 2012), a prevalence that may rise further in adults (Chung et al., 2016).

Our understanding of the role of the innate immune response in $\mathrm{OM}$ is improving as more evidence comes to light that frequent or prophylactic antibiotics are not always effective for chronic or recurrent forms of OM, or even for non-severe AOM, where a "watch and wait" approach to treatment is recommended (Lieberthal et al., 2013). In many clinical practice guidelines, antimicrobial decision-making is based on the clinical severity of AOM (Spoiala et al., 2021), with a previous randomised control trial in high-risk individuals reporting that long-term antibiotics did resolve OME and prevent AOM with perforation (Leach et al., 2008). However, for chronic forms of OM, such as CSOM, the benefits of either systemic or topical antibiotics for rapid resolution are not clear (Chong et al., 2021), and analgesics rather than antibiotics or anti-inflammatories are recommended as the front line treatment for OME (Rosenfeld et al., 2016; Chong et al., 2021).

The innate immune system is a critical first line of defence within the middle ear and is activated in response to pathogen associated molecular patterns (PAMPs) on invading pathogens (Li et al., 2013; Massa et al., 2015). Key characteristics of this defence mechanism include physical epithelial barriers, recognition of non-self-factors such as pathogens, upregulation of the complement system, initiation of generalised inflammatory responses and activation of specific immune responses to pathogens through upregulation of the adaptive immune system (Massa et al., 2015; Preciado et al., 2017).

\section{BACTERIAL AND VIRAL OTOPATHOGENS}

Historically, the middle ear has been considered a sterile environment (Kurono et al., 1996; Lim et al., 2000). However, recent advances in 'OMICS technology have revealed the potential of a middle ear microbiome (Marsh et al., 2020). The mechanisms by which the middle ear microbiome, in concert with that of the nasopharyngeal microbiome, may impact on the development and pathogenesis of OM remain largely unknown. This is a growing area of investigation (Schenck et al., 2016; Enoksson et al., 2020; Marsh et al., 2020), as the presence of a healthy middle ear microbiome is controversial (Johnston et al., 2019) with one key study in adults finding no evidence of bacterial colonisation of the middle ear using microscopy and culture techniques (Jervis-Bardy et al., 2019). The inflammation that defines OM, however, is induced by invading respiratory viral pathogens and dysregulated commensal bacterial populations within the nasopharynx, which then migrate through the upper respiratory tract via the eustachian tubes to infect the middle ear. How well these infections are then controlled by host mucosal immune responses, and the nature of each individual's immune response, direct the course of OM disease.

Three bacterial species, Streptococcus pneumoniae, nontypeable Haemophilus influenzae (NTHi) and Moraxella catarrhalis are the dominant bacterial otopathogens globally (Schilder et al., 2016) although individual species and strain dominance may vary according to geographical location (Ngo et al., 2016). These bacteria are commensal in the nasopharynx and typically do not induce localised inflammation or activation of innate immune responses, however their presence within the middle ear stimulates both responses and may result in clinical presentation of AOM.

Functional, effective clearance of bacterial otopathogens from the middle ear, particularly for children experiencing RAOM and 
COME, may be disrupted by the presence of bacterial biofilm development on the epithelium of the middle ear (Hall-Stoodley et al., 2006; Thornton et al., 2011). Mucosal biofilms result from host and bacterial interactions, often multiple bacterial species (Thornton et al., 2011), incorporating host and bacterial DNA to develop and stabilise the biofilm. Furthermore, in addition to biofilms, the presence of intracellular bacteria, within the mucosal epithelial cells may also contribute to OM persistence and ineffective clearance of infection through antibiotic use (Bakaletz, 2012; Coates et al., 2008).

Viruses play an important role in the induction of AOM, which often occurs as a complication of upper respiratory infection (URTI) (Pettigrew et al., 2011). Some viruses can cause AOM in isolation, although most cases of AOM are the result of polymicrobial infections (Ruohola et al., 2013; Sawada et al., 2019). All respiratory viruses have been associated with $\mathrm{AOM}$, in that they have been detected in middle ear fluid (MEF) or by nasopharyngeal swab during an episode of AOM, although some are more commonly detected than others (Pettigrew et al., 2011; Sawada et al., 2019). These include rhinovirus (RV), respiratory syncytial virus (RSV), adenovirus (AdV), human metapneumovirus (HMPV), influenza A virus (IAV) and seasonal human coronaviruses (Heikkinen et al., 1999; Chonmaitree and Heikkinen, 2000; Chonmaitree and Henrickson, 2000; Heikkinen and Chonmaitree, 2003; Kalu et al., 2011; Nokso-Koivisto et al., 2015; Chonmaitree et al., 2016; Schilder et al., 2016). In many studies, rhinovirus is the most common virus detected in both MEF and the nasopharynx of children with AOM (Moore et al., 2010; Yatsyshina et al., 2016), while in other studies RSV is most commonly detected (Sawada et al., 2019). Some viruses, however, are considered more "otopathic" than others, in that they are more likely to cause AOM without bacterial co-infection. A study that investigated the seasonality of AOM identified that peak AOM activity was significantly associated with detection of RSV, HMPV and IAV (Stockmann et al., 2013). RSV in particular is known to induce AOM in the absence of bacterial infection of the middle ear (Ruohola et al., 2013; Yatsyshina et al., 2016). There is substantive clinical evidence that IAV and RSV enhance the severity of OM (Heikkinen et al., 1999).

It is becoming increasingly apparent that defects in the host innate immune response of the middle ear drive prolonged inflammation, reduce pathogen clearance, and underlie chronic and recurrent forms of OM. This review explores the innate immune response to both viral and bacterial pathogens in $\mathrm{OM}$, and current knowledge regarding the dysregulation of the host immune response that may underlie the development and recurrence of OM. Animal experimental models, in addition to clinical studies, are discussed, since investigating immune responses to pathogens in isolation in the middle ear is difficult, and mechanistic studies using a range of animal models are essential. However it needs to be noted that murine immune responses may differ to those of humans and so need to be viewed in the context of complementary studies (Bhutta, 2012; Tyrer et al., 2013). A focus of this review is the host innate immune response to NTHi, as the most common otopathogen used to investigate host immune mechanisms using animal models for OM. In contrast, respiratory virus activation of host innate immune responses in OM pathogenesis is less clear, with most fewer animal model studies focussed on the role of IAV and RSV.

\section{PATHOGEN RECOGNITION AND ACTIVATION OF SIGNALLING PATHWAYS WITHIN THE INNATE IMMUNE RESPONSE}

Within the middle ear, like other mucosal immune locations, molecular signatures known as pathogen-associated molecular patterns (PAMPs), are produced by both bacterial and viral pathogens and recognised via one or multiple microbial pattern recognition receptors (PRRs) (Medzhitov, 2007; Kawai and Akira, 2009; Li and Chang, 2021). These receptors are located throughout the middle ear epithelium, and are expressed on the cell surface, internal cell membranes and within the cytoplasm of structural epithelial and antigen presenting cells within the host innate immune system (Leichtle et al., 2011; Kumar et al., 2013; Kurabi et al., 2016).

Non-self-DNA and RNA sensing within the middle ear mucosa can involve multiple PRRs depending on the invading pathogen and intrinsic host PRR expression. Overall, this activation of multiple PRRs during the initial innate immune response to pathogens provides increased opportunity for multiple synergistic and/or redundant signalling pathways to be activated, often through $\mathrm{NF}-\mathrm{\kappa B}$, interferon response factors (IRFs) and AP-1 transcription factor activation (see Figure 1). The efficacy of different signalling pathways can influence host susceptibility to disease (Skevaki et al., 2015). Signalling regulation by host and pathogen factors within the middle ear during $\mathrm{OM}$ may lead to modification of timing and secretion of various cytokines, chemokines, interferons, and antimicrobial peptides from the mucosal epithelium or cells recruited to the site of activation. Importantly, the concentrations of antimicrobial peptides and proteins, and cytokines within MEF of children experiencing recurrent AOM are known to increase (Seppanen et al., 2019).

Host innate immunity is activated in response to a wide range of bacterial and viral pathogens through transcription factors downstream from the PRRs and can vary to provide stimulusspecific responses (Borghini et al., 2018). This regulation of the innate immune response is essential to optimise pathogen clearance whilst minimising local tissue damage from inflammatory processes (Massa et al., 2015). For example, PRR activation of the NFKB transcription factor cascade by NTHi increased surfactant protein A (SP-A) expression in SP-A knockout mice, causing more severe inflammation. In contrast, wild-type mice showed improved bacterial aggregation, killing and macrophage clearance of the middle ear due to SP-A modulation of the host inflammatory response (Abdel-Razek et al., 2019).

Thus, differences in host PRR expression and subsequent signalling pathway activation can lead to differences in how the 


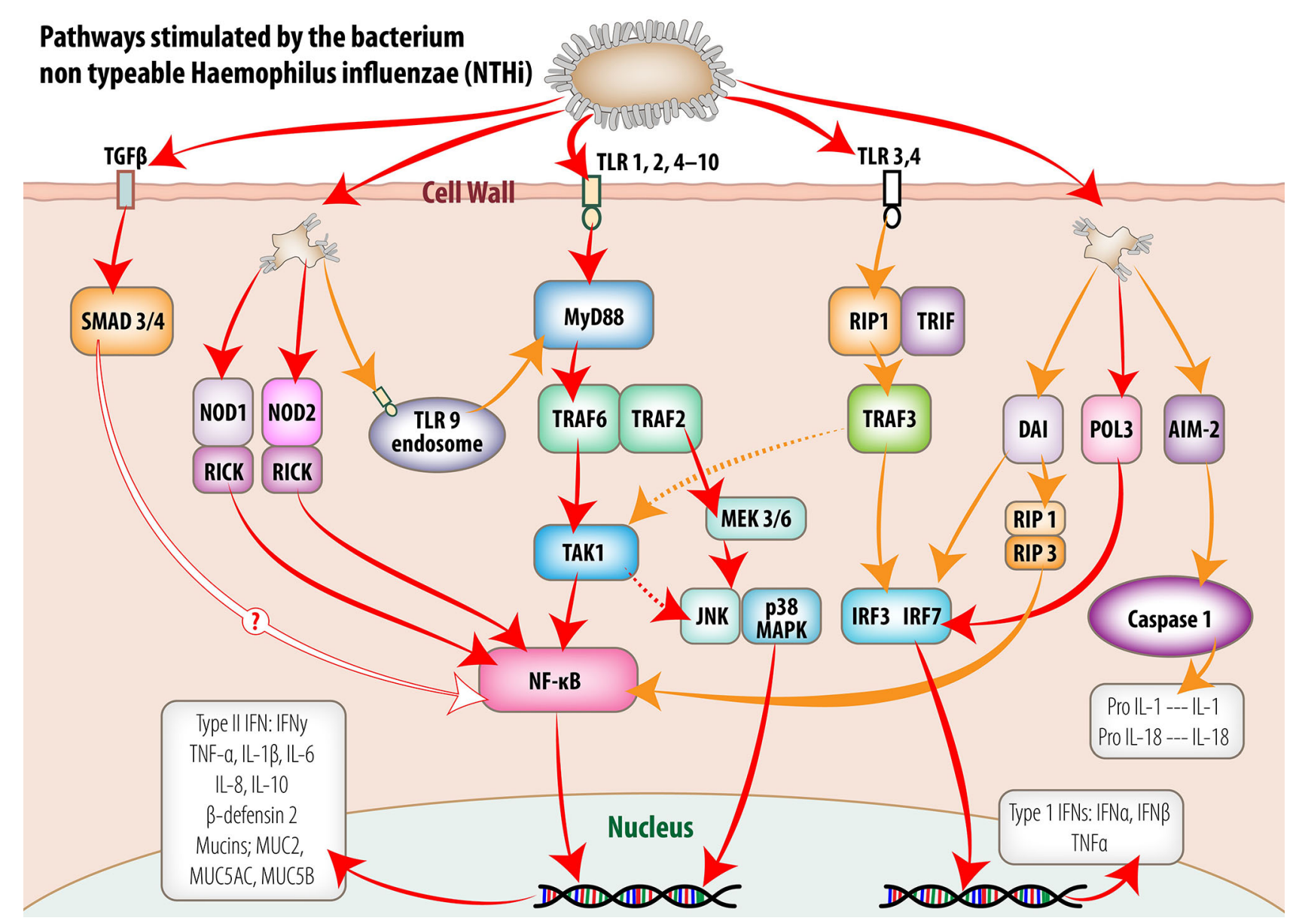

FIGURE 1 | Intracellular signaling pathways utilized by middle ear mucosa in response to stimulation by non-typeable Haemophilus influenzae (NTHi). Pattern recognition receptors (PRR) detect conserved molecular signatures of invading microbes and facilitate activation of synthesis and secretion of downstream cytokine cascades. This figure schematically represents the signaling pathways activated by NTHi both at the cell membrane and within the cell cytoplasm of the middle ear mucosal cells. The information portrayed was extracted from published reports of experiments utilizing middle ear cell lines and middle ear epithelium and mucosa from animal models and human biopsy material. (Reproduced, with permission, Massa et al., 2015).

innate immune response is regulated and how OM disease progresses. There is growing evidence that host genetic polymorphisms in PRR genes and differences in PRR expression can dysregulate innate immune signalling pathways in response to otopathogens and therefore play a significant role in the induction and pathogenesis of OM (Lin et al., 2017). Furthermore, NTHi is recently reported to utilise phase variable epigenetic regulation to modify and adapt its phenotype but also modify host immune responses (Robledo-Avila et al., 2020), creating a shifting immunological target for the host (Parrish et al., 2019).

\section{PRR ACTIVATION AND INNATE IMMUNE SIGNALLING IN RESPONSE TO BACTERIAL OTOPATHOGENS}

Toll-like receptor (TLR)-dependent activation of innate immune responses within the middle ear are currently best described from animal, particularly murine models. In these models, the cell surface-expressed TLRs, TLR-2 and TLR-4, play an important role in sensing and responding to bacterial otopathogens (Kweon et al., 2006; Moon et al., 2007; Trune and Zheng, 2009; Kim et al., 2010; Leichtle et al., 2011; Mittal et al., 2014b; Zhang et al., 2015). The overall effect TLR activation is to induce NF- $\kappa \mathrm{B}$ signalling, resulting in mucosal hyperplasia and upregulation of pro-inflammatory cytokines (Lim et al., 2007) (see Figure 1). Thus, TLRs initiate and mediate expression of a variety of molecules from the middle ear mucosa including inflammatory cytokines (IL-1 $\alpha$, IL-1ß, IL-6, IL-10, TNF $\alpha$, vascular endothelial growth factor (VEGF), chemokines $\mathrm{Ccl} 3$ (macrophage inflammatory protein 1a or MIP1a), Cxcl2 (macrophage inflammatory protein-2 or MIP2), keratinocyte-derived chemokine (KC or Cxcl1; recruits and activates macrophages) and antimicrobial peptides such as mouse $ß$-defensin 2 and mucin genes (MacArthur et al., 2011; Trune et al., 2015; Kurabi et al., 2016). Interestingly, in 
association with changes in epithelial cell structure from pseudostratified ciliated columnar epithelium within the eustachian tube to a more squamous epithelium within the middle ear of the rat (Massa et al., 2015), more TLR2 and TLR4 receptor mRNA is expressed within the middle ear compared to other upper respiratory tract locations including the Eustachian tube, nasopharynx and oral cavity (Song et al., 2009). The essential role of TLR2 and TLR 4 receptors and signalling molecules, MyD88 and TRIF in the activation of innate immune responses has also been demonstrated using knock-out murine models (Hernandez et al., 2008; Leichtle et al., 2009). Gene deletion of these receptors and signalling molecules results in persistent OM, in the form of thickened mucosa, delayed neutrophil and macrophage recruitment and reduced efficiency of bacterial killing and clearance from the middle ear (Leichtle et al., 2009; Leichtle et al., 2011; Underwood and Bakaletz, 2011; Kurabi et al., 2016).

The importance of cell surface TLR signalling in the innate immune response in OM is best demonstrated in a murine model in which heat-killed NTHi was used for trans-tympanic inoculation (MacArthur et al., 2006; Trune et al., 2015). In these mice, there was no active infection within the middle ear, although an inflammatory response was still induced in response to endotoxins, which act as PAMPs. Within $6 \mathrm{hrs,} \mathrm{genes} \mathrm{for} \mathrm{MIP-}$ $1 \alpha$, MIP-2 $\alpha$, IL- 6 and Cxcl1 demonstrated significantly elevated expression (>50->1000 fold) whilst IL-1 $\alpha$ (Ccl3), IL-1ß, IL-10, TNF $\alpha$ expression was more moderately upregulated $(>4->36$ fold). Expression of each of these genes returned to nonstimulated levels by $72 \mathrm{hr}$ in the absence of active infection. Cytokine and chemokine production was increased in parallel with the gene upregulation, however the production of these proteins lagged behind upregulated gene expression by peaking $24 \mathrm{hr}$ after inoculation. In this model, TLR4 and TLR9 expression were also significantly increased, while TLR2 expression was only slightly increased (Trune et al., 2015). Interestingly, NTHi infection also increased Chemokine CXC receptor 4 expression in the mouse middle ear model, signalling the inflammatory response through IKK $\alpha$ and p38MAPK pathway activation (Ma et al., 2018). Studies using bacterial otopathogens other than NTHi are limited, however, it has been demonstrated in a mouse pneumococcal OM model that TLR2 expression and NF- $\mathrm{KB}$ signalling in the middle ear mucosa, is critical for the recruitment of macrophages. The absence of TLR2 expression resulted in impaired $S$. pneumoniae clearance from the middle ear and a prolonged inflammatory response (Komori et al., 2011; Huang et al., 2016).

Observations regarding the importance of TLR2 in the innate immune response in murine models of OM is supported by clinical studies. In children, TLR2 is a predominant NTHi receptor within middle ear epithelial cells and activation of this receptor leads to the induction of $\beta$-defensin 2 through activation of the MyD88-IRAKI-TRAF6-MKK3/6-p38 MAP kinase signal transduction pathway (Lee et al., 2008). Increased mRNA expression of TLR4 and TLR2 has also been reported within the middle ear fluid (MEF) of children experiencing AOM, with TLR9 expression remaining unchanged. Coincident with the
TLR upregulation, mRNA expression of cytokines including, pro-inflammatory TNF $\alpha$, IL-6, IL-8, IL-10, IL-1 $\beta$ and chemokines CCL2, CCL3, CCL4, CCR5 and CXCR3 were significantly higher (8-330 fold) in bacterial culture positive MEF samples, and increased mRNA expression of these molecules was associated with increased numbers of bacterial species identified within the sample (Kaur et al., 2015).

In addition to cell surface expressed TLR signalling, endosomal TLR9 was shown to be important in sensing NTHi when inoculated into the murine middle ear. Deletion of TLR9 from mice prolonged middle ear inflammation and bacterial clearance (Leichtle et al., 2012). In this same study, Leichtle et al, also identified non-TLR pathogen DNA sensing genes to be upregulated in response to infection by NTHi. These included DNA-dependent activator of IFN regulator factor (DAI), absent in melanoma-2 (AIM2) and Pol-III in addition to other genes encoding proteins that mediate downstream signalling pathways (Leichtle et al., 2012).

Several other families of PRRs contribute to PAMP recognition and activation of the signalling pathways to activate and modulate innate immune responses, including retinoic acid-inducible gene 1 (RIG-I)-like receptors (RLR's), cytoplasmic nucleotide-binding oligomerisation domain (NOD)-like receptors (NLRs) and DNA sensing receptors (Kurabi et al., 2016). Compared to surface expressed TLR receptors, less is known concerning the importance of cytoplasmic PRRs in sensing and responding to bacterial infections in the middle ear (Kumar et al., 2011; Kurabi et al., 2016). However cytoplasmic NOD-like receptors and RIG-1 receptors exhibit reduced expression in patients with $\mathrm{OM}$ which may be associated with the development of recurrent OME (Kim et al., 2014). NOD1/NOD 2 receptors activate innate immune responses during $\mathrm{OM}$ to reduce infection (Lee et al., 2019). More specifically, NOD2 mediated $\beta$-defensin 2 regulation is activated after NTHi penetration of the cell membrane and helps to prevent OM development (Woo J. I. et al., 2014). Activin-like cell surface receptor kinases and serine/ threonine kinases also activate important signalling pathways in the pathogenesis of OM. These receptors lead to the activation of TGF- $\beta$, which is a pleiotropic cytokine and a key regulator of tissue remodelling.

Although several murine models of bacterial OM have demonstrated an upregulation of pro-inflammatory responses to infection within the mucosa, the entire process of immunoregulation during OM may be more complex. A report on the transcriptome signature elicited from PBMCs at the onset of AOM in children caused by NTHi reported that genes associated with antibacterial activity and cell-mediated immunity were predominantly affected. Importantly, the study suggested that NTHi infection suppressed more immune responses than were activated. More specifically, 90\% of genes associated with pro-inflammatory cytokine responses were down-regulated, as was classic complement pathway activation (Liu et al., 2013). Furthermore, the transcriptome of a complete episode of NTHi-induced AOM in a mouse model was examined via expression profiling utilising whole genome microarrays in 
the murine model. Sets of genes involved in activation of the innate immune response, negative regulation of that response, epithelial and stromal cell marker changes and neutrophil and macrophage recruitment and function were identified. Overall, positive and negative regulation of inflammatory processes were recognised, and the importance of anti-inflammatory responses in control of OM pathogenesis were highlighted (Hernandez et al., 2015). Importantly, regulation of NTHi triggered activation of inflammatory responses by natural products such as the plant pigment Quercetin may provide potential therapeutic approaches to reduce OM (Ma et al., 2018).

\section{VIRUS-INDUCED INNATE IMMUNITY}

Respiratory viruses alone can induce $\mathrm{AOM}$ and lead to chronic presentations of OM (Heikkinen and Chonmaitree, 2000). A causal relationship between viral URTI and eustachian tube obstruction, middle ear pressure and bacterial colonisation has been demonstrated in both human challenge studies using rhinovirus (McBride et al., 1989; Buchman et al., 1994) and IAV (Doyle et al., 1994) and in both chinchilla and mouse models of AOM induced by IAV (Giebink et al., 1987; Short et al., 2011). In addition, viral-bacterial coinfections have demonstrated more severe outcomes for AOM in humans (Moore et al., 2010; Binks et al., 2011; Pettigrew et al., 2011; Chonmaitree et al., 2016; Schilder et al., 2016) and animal models (Giebink and Wright, 1983; Patel et al., 1992; Brockson et al., 2012), compared to bacterial colonisation alone. However, despite this clear link between respiratory virus infections and $\mathrm{OM}$, the exact mechanisms by which viruses promote the development of AOM and subsequent chronic and recurrent $\mathrm{OM}$ is not well known due to a paucity of studies on the immune response during virus-only AOM. Therefore, our understanding of the role of respiratory viruses in the immune response during $\mathrm{OM}$ is based largely on our general understanding of the immunopathology of URTIs, which affect the nasopharynx foremost with AOM considered a secondary complication (Heikkinen, 2000; Chonmaitree et al., 2008; Bakaletz, 2010; Kalu et al., 2011; Chonmaitree et al., 2016).

There are few human clinical studies that have sought to characterise the immune response to respiratory viruses during $\mathrm{OM}$ and understand how this contributes to pathogenesis of disease. One study collected sera from 145 children with AOM and found that RSV-associated AOM correlated with elevated serum concentrations of proinflammatory cytokines (Patel et al., 2009a). These included G-CSF, MCP-1, IL-10, IL-6, IFN- $\gamma$ and IL-8, with G-CSF concentrations predicting RSV-associated OM with $87 \%$ accuracy. In this study, local mucosal responses were not investigated, although in a related study, the cytokines detected in nasopharyngeal secretions of 326 children with virus-positive URTIs were identified and correlated with virus identification and the onset of AOM (Patel et al., 2009b). All viruses detected (adeno-, entero- rhino- viruses, RSV, Parainfluenza viruses, Influenza viruses) induced significant quantities of IL-1 $\beta$, IL- 6 and TNF $\alpha$. However only IL-1 $\beta$ was significantly associated with the onset of AOM and was not correlated with any particular virus.

Some studies have identified innate immune responses of cultured human middle ear epithelial (MEE) cells when infected with IAV. A transcriptional study of cells up to $24 \mathrm{~h}$ post infection revealed upregulation of genes encoding an array of type I interferon inducible signalling pathways, transcription factors, cytokine and chemokine genes, as expected in response to viral infection (Tong et al., 2004). MEE cells also secrete elevated levels of MIP- $1 \alpha$ and MIP- $1 \beta$, TNF- $\alpha$, IL-6, IL- 8 and IL-10 in response IAV infection (Tong et al., 2003; Tong et al., 2004). Interestingly, when IAV strains were compared, H3N2 IAV induced a stronger IL- 6 and IL- 8 response by MEE cells in culture than H1N1 (Short et al., 2013).

These human studies are informative regarding antiviral responses, although do not provide mechanistic detail regarding how the immune response to viral infections drives the development of OM. Animal models have been used to understand the role of viral URTIs in the development of OM. However, very few have focused on the induction of AOM by viruses alone, without bacterial involvement. Early chinchilla models demonstrated clinical signs and symptoms of OM induced by viruses alone (Giebink et al., 1987), including general observations of tympanic membrane inflammation (Giebink and Wright, 1983). Short et al. (2011) developed the first infant murine model of IAV-induced AOM (Short et al., 2011), where IAV replicated in the middle ear epithelium, and caused submucosal edema and an influx of immune cells, predominantly neutrophils, into the middle ear cavity. These mice also displayed hearing loss indicative of clinical AOM. In a follow up study, inoculation of mice with recombinant IAVs identified a pro-inflammatory response in the middle ear, specific to replicating viruses with a H3-type HA attachment viral protein. This response was dominated by upregulation of genes expressing IL-1 $\beta$, IL- $1 \alpha$ and CXCL2 in the middle ear (Short et al., 2013).

\section{INNATE IMMUNE RESPONSES TO POLYMICROBIAL INFECTIONS}

Adding to the complexity of the host innate immune responses, microbe to microbe interactions are being recognised within the upper respiratory tract microbiome (Schenck et al., 2016) which may enhance or impair bacterial competition and the host innate immune response. For example, peptidoglycan secretion by $H$. influenzae can activate neutrophils to enhance complementdependent killing of S. pneumoniae (Lysenko et al., 2005), whilst S. pneumoniae can impair NTHi evasion of host immune responses (Shakhnovich et al., 2002). Furthermore, S. pneumoniae and NTHi can synergistically upregulate TLR2 expression, increasing inflammation (Ratner et al., 2005).

Most mechanistic studies in animal models of OM have used single infections to understand cause and effect. However, polymicrobial animal models for OM more closely replicate the complex microbial environment of the nasopharynx and 
infected and/or inflamed middle ear (Bakaletz, 2010), and may better reflect COM pathogenesis (Holder et al., 2012) and immunisation responses (Novotny et al., 2017). A rat model of $\mathrm{OM}$ involving dual infection of the middle ear with NTHi and Pneumococcus type 6A (Pn6A) demonstrated upregulation of genes encoding inflammatory Th2 cytokines and effectors of the TGF- $\beta$ signalling pathway, which resulted in pathogenic changes and thickening of the mucosa and submucosal layers of the middle ear during OM (Lee et al., 2011). It has been demonstrated in chinchilla that middle ear infection with NTHi promotes the persistence of $M$. catarrhalis via the formation of polymicrobial biofilms (Armbruster et al., 2010). In a mouse model, $M$. catarrhalis impacted pneumococcal OM more than NTHi regarding bacterial load, incidence rate and persistence of infection. Nitric oxide was measured as an indication of inflammation and was elevated in polymicrobial infections significantly more than single infections. Interestingly, pre-infections with the respiratory virus, Sendai Virus, enhanced bacterial OM for all three otopathogens, demonstrating the importance of viral infection in the development of bacterial OM (Krishnamurthy et al., 2009).

Most animal models of virus-induced OM have investigated the role of viruses in supporting subsequent bacterial colonisation of the eustachian tube and middle ear. The chinchilla model has been the most utilised to study the pathogenesis of viral-bacterial co-infection in OM (Giebink and Wright, 1983; Suzuki and Bakaletz, 1994). However, it does have limitations, in that the immune responses and the presentation of AOM in these animals can vary depending on the order and timing of infection and partnering of viruses and bacteria. These variables have made it difficult to build an accurate picture of the role of antiviral innate immune responses in AOM. It has also been difficult to identify specific mechanisms by which viral dysregulation of the innate immune response promotes bacterial colonisation. Therefore, most studies report general inflammation and clinical signs of $\mathrm{OM}$ on tympanometric investigation of animals.

Murine models of IAV and S. pneumonia co-infection have demonstrated more severe AOM than single infections of either virus or bacteria alone, including greater hearing loss, and middle ear inflammation (Short et al., 2013), in addition to reduced ciliation, hyperplasia of the mucosal epithelium and increased goblet cells (Tong et al., 2014). Tong et al. (2104) also identified that the anaphylatoxins $\mathrm{C} 3 \mathrm{a}$ and $\mathrm{C} 5 \mathrm{a}$ were expressed in both serum and middle ear lavage from IAV-infected mice indicating that induction of the complement alternative pathway reduced bacterial clearance and enhanced the severity of acute pneumococcal OM. When paired with $M$. catarrhalis and NTHi in experimental Chinchilla infections, RSV was associated with clinical signs of inflammation and haemorrhagic foci in the middle ear mucosa (Brockson et al., 2012), thus compromising the ability of the mucosa to combat ascending bacterial infections and biofilm formation in the middle ear. The chinchilla model has also been useful in demonstrating the ability of different viruses in enhancing bacterial OM. Type 5 adenovirus (Ad5) has been shown to promote infection of the middle ear by S. pneumoniae (Murrah et al., 2015), while type 1 adenovirus (Ad1) has been shown to promote ascension of NTHi (Suzuki and Bakaletz, 1994) although not S. pneumoniae (Tong et al., 2000) or $M$. catarrhalis (Bakaletz et al., 1995). It is likely that the role of viruses in $\mathrm{OM}$ is complex and involves not only inflammation and innate immune dysregulation, but also other factors that enhance bacterial colonisation such as epithelial damage, mucus production and modulation of antimicrobial peptides, as has been demonstrated within other compartments of the respiratory mucosa (Melvin and Bomberger, 2016).

\section{ANTIMICROBIAL FACTORS RELEASED BY THE MUCOSAL EPITHELIUM}

In addition to classical innate and adaptive immune responses, the production of anti-microbial molecules, mucus secretion, and mucociliary clearance within the middle ear and eustachian tubes, work in combination to maintain the relative sterility of the middle ear cavity (Lim et al., 2000; Massa et al., 2015). Morphologically, the middle ear region adjacent to the eustachian tube and the eustachian tube itself, exhibit cellular characteristics shared by other mucosal surfaces within the upper respiratory tract, such as a secretory, pseudostratified, and ciliated columnar epithelium (Lim, 1976; Lim, 1979; Bluestone and Doyle, 1988; Martin et al., 2017). The physical resilience of the epithelium is reinforced via tight junctions (Tsukita et al., 2008; Yonemura, 2011) and goblet cells that secrete mucus to provide a barrier to adherence and colonisation by bacteria, (Linden et al., 2008), and contribute to the mucociliary clearance of the tympanic cavity and eustachian tube (Evans and Koo, 2009; Martin et al., 2017).

Most importantly, the mucosal response includes activation of antimicrobial molecules, such as lysozyme, ß-defensins and lactoferrin which either independently or together, act to inhibit bacterial colonisation and activate the adaptive immune response (Underwood and Bakaletz, 2011). The significance of antimicrobial molecules has been demonstrated using animal models. For example, lysozyme knockout mice exhibit increased susceptibility to bacterial colonisation of the middle ear and enhanced inflammatory response to $S$. pneumoniae $6 \mathrm{~B}$ infection (Shimada et al., 2008). Furthermore, in humans, lysozyme and Bdefensin 2 can synergistically partner to directly kill invading $S$. pneumoniae 6B (Lee et al., 2004) and protect against NTHi induced OM (Woo J. I. et al., 2014). Most recently, a study examining middle ear effusate from children experiencing recurrent AOM confirmed the importance of elevated antimicrobial protein (AP) and cytokines as potential markers for bacterial persistence and inflammation (Seppanen et al., 2019). Antimicrobial proteins or host defence peptides may offer future treatment options against polymicrobial infections (Bergenfelz and Hakansson, 2017; Batoni et al., 2021).

Viruses, conversely, have been shown to enhance bacterial infection of the middle ear by suppressing antimicrobial factors and enhancing bacterial adhesion molecules. McGillivary et al. (2007) 
demonstrated that both viruses and bacteria can alter the expression of cationic APs in the upper airways, thus enabling an expansion of otopathogens. This elegant study involved the expression of recombinant cCRAMP, a cathelicidin homolog from the upper respiratory tract of the chinchilla in cultured chinchilla middle ear epithelial cells (CMEEs). CMEEs were infected with IAV, RSV or Ad1, and the effect on CCRAMP and also cBD-1, which is the murine ortholog of the human AP $\beta$-defensin, was investigated (McGillivary et al., 2007). IAV reduced cCRAMP mRNA expression by $50 \%$, while RSV and Ad1 only had a minimal effect. In contract RSV reduced the expression of cBD-1 mRNA by $40 \%$, while IAV and Ad1 did not. Thus, highly otopathic viruses, such as IAV and RSV appear adept at differentially reducing key antimicrobial defence molecules in airway epithelial cells using different mechanisms. The ability of RSV to suppress cBD-1 expression has also been demonstrated directly in a chinchilla RSV/NTHi co-infection model. In this model, RSV intranasal challenge diminished both cBD-1 mRNA and protein expression in the upper airway epithelium. Consequently, when chinchilla were inoculated with NTHi, there was a marked increase in both the quantity and duration of NTHi recovered from the nasopharynx (McGillivary et al., 2009). These studies provide evidence that virus-induced dysregulation of AP expression contributes to the elevated bacterial colonisation to precedes AOM (Bakaletz, 2010).

The net effect of viral URTI is a reduction in the protective function of the mucosal epithelium, which extends from the nasopharynx through the eustachian tubes and into the middle ear. This compromise in protection renders the middle ear susceptible to ascending bacterial infection, and can last from 2-10 weeks in children before homeostatic conditions are returned (Carson et al., 1985).

\section{IMMUNOCOMPETENT CELL TYPES WITHIN THE MUCOSAL EPITHELIUM}

The healthy middle ear of both humans and animal models of $\mathrm{OM}$ is host to immunocompetent cell types, although not in significantly high numbers until infiltration occurs during AOM (Jecker et al., 1996; Jecker et al., 2001; Suenaga et al., 2001) or COME (Enoksson et al., 2020). Mast cells and macrophages are the predominant cell types in non-inflamed middle ear, with dendritic cells and macrophages present in the tympanic membrane (Ichimiya et al., 1990; Mittal et al., 2014b) These antigen-presenting cell phenotypes provide a mechanism for interconnection of the local innate mucosal immune response with the more specific adaptive immune system (Ichimiya et al., 1997). Enhanced inflammation within the middle ear mucosa, stimulated through pro-inflammatory cytokine secretion including $B$-defensin 2 and other defensins (Underwood and Bakaletz, 2011) and pre-inflammatory molecules including TNF $\alpha$, IL-1 $\beta$ and CCL3, attract other immunocompetent cells via chemotaxis, including dendritic cells, memory T-cells, neutrophils and mast cells within the epithelium (Yang et al.,
2007). In addition to direct bacterial killing, ß-defensin 2 contributes to the mediation of adaptive immunity (Yang et al., 2007; Underwood and Bakaletz, 2011).

Upregulation of the innate immune response, as evidenced by immunocompetent cell infiltration, has long been demonstrated in COM patients (Palva et al., 1981; Enoksson et al., 2020), whilst mouse models of NTHi infection of the middle ear have also demonstrated leukocyte infiltration (Hernandez et al., 2008; Hernandez et al., 2015; Trune et al., 2015). Furthermore, the acute inflammatory response during AOM in the rat model shows time-dependent increases in identification of macrophages, dendritic cells, polymorphs and natural killer cells (Jecker et al., 1996; Forseni et al., 1999), with T-cells present 3 days after perforation of the tympanic membrane (Tahar Aissa and Hultcrantz, 2009).

The activation and rapid response of the innate immune response within the middle ear mucosa is well evidenced from animal studies, particularly mouse models (Bhutta, 2012). Evidence of the precise timing and duration of immunocompetent cell changes occurring in the murine middle ear demonstrates that neutrophil recruitment is evident within $6 \mathrm{hrs}$ of inoculation of middle ear and peaks 24 hours post inoculation at level $\sim 10$-fold greater than the peak recruitment of macrophages observed at 48 hours after inoculation (Leichtle et al., 2011). The number of neutrophils within the ME epithelium returned to control levels after $72 \mathrm{~h}$, whereas macrophages were still observed $120 \mathrm{hr}$ post inoculation. Epithelial effusion within the middle ear is present 24$48 \mathrm{hr}$ post inoculation, consistent with peak neutrophil and macrophage (Hernandez et al., 2015) recruitment. Unfortunately, increased neutrophil recruitment can be utilised by NTHi to avoid phagocytosis through host formation of neutrophil extracellular traps (Juneau et al., 2011; Schachern et al., 2017) which have been identified within the MEF of children with OM (Thornton et al., 2013).

Neutrophil infiltration of the middle ear is also a feature of IAV-induced OM in a murine model (Short et al., 2011). IAV also depressed polymorphonuclear leukocyte chemiluminescence activity in a chinchilla model (Giebink and Wright, 1983). Interestingly $\mathrm{H} 3 \mathrm{~N} 1$ had a more significant effect on this response than H1N1, similar to the findings of Short et al. (2013).

\section{INNATE IMMUNE RESPONSE ACTIVATION OF THE ADAPTIVE IMMUNE RESPONSE}

Overall, there is a paucity of human studies, however, many murine studies have explored the interconnection of the innate immune responses occurring within the middle ear and their role in activation of the adaptive immune response. Within 3 days post inoculation with type B Haemophilus influenzae, macrophages and Mac-1+ neutrophils were present in the middle ear of mice whilst within the middle ear mucosa, Lyt-1+ T cells and Lyt-2+ T suppressor/cytotoxic cells were present 7 and 14 days post inoculation. The majority of mucosal immunoglobulin-bearing cells at Day 14, were IgA+ lymphocytes although IgG+ and IgM+ $\mathrm{T}$-cells were present 3, 7 and 14 days post-inoculation. Lyt-1/ 
L3T4+ T lymphocytes were present in larger numbers than B lymphocytes thus helper $\mathrm{T}$ cells appear to have significant involvement in AOM (Krekorian et al., 1991). Recent profiling of the cells within the murine middle ear using single-cell transcriptomics identified 17 different cell clusters, reflecting different cell types within the normal middle ear however tissue monocytes appear to have a primary role in regulation of acute middle ear infection response in the complex innate defence (Ryan et al., 2020). Interestingly, adaptive immune system factors such as TBX21, a transcription factor, may also participate in innate immune response regulation during $S$. pneumoniae infection, through modifying TLR2 expression (Woo C. H. et al., 2014). Whilst these model studies establish a link between innate and adaptive immune responses in the middle ear, additional studies are needed to confirm such links in the human middle ear.

Recent evidence highlights the complexity of the upregulation of specific inflammatory cells and mediator secretion varies in response to the microbial otopathogens involved and the child's gender, with Moraxella and Haemophilus species tending to stimulate more inflammatory mediators in the middle ear (Enoksson et al., 2020). Interestingly, within the few human studies available, reports of relationships between IgG, IgG1, IgG2 and IgA are complicated by case-definitions of the sampled population (Corscadden et al., 2013). A well-designed crosssectional study of serum and middle ear levels of IgG, IgG1 and IgG2 in children under 3 years of age, with and without a history of frequent AOM reported that of 11 different pneumococcal serotypes present, only serotype 5 induced elevated serotype specific IgG and IgG1. This study evidenced that frequent AOM is not the result of deficiency in IgG, IgG1 or IgG2 response (Corscadden et al., 2013). Further research, focussed on both viral and bacterial otopathogens are needed to the confirm the innate activation of the adaptive immune responses of children experiencing OM.

\section{HOST FACTORS THAT MODULATE THE MUCOSAL RESPONSE IN OM}

In this review we have explored the innate immune response to predominant otopathogens in the context of OM pathogenesis. Induction of a productive innate immune response that will clear otopathogen infection, whilst minimising inflammation is ideal for AOM resolution, while a hyperinflammatory response and upregulation of bacterial adhesion mechanisms is deleterious to this process and may result in recurrent or chronic forms of OM. Otitis media susceptibility is associated with a number of host genes, identified in previous reviews (Kurabi et al., 2016; Bhutta et al., 2017; Geng et al., 2019). Genetic factors that influence the heritability of susceptibility to OM are reported to range between 40\%-70\%, based on several prospective, longitudinal prospective and retrospective twin studies (Mittal et al., 2014a). In humans, reduced expression of key PRRs TLR9, NOD1, NOD2 and RIG-I has been observed in the MEF of OM-prone compared to nonOM-prone children (Kim et al., 2010). In addition, TLR2, IL-1, IL- 6 and TNF $\alpha$ gene and protein production were reduced in children aged 2-7 years compared to 0-2 and over 7-year olds, and were also lower in culture-positive OM (Kim et al., 2015). Interestingly, in contrast, one report identified no significant differences in mRNA and protein levels of TLR2, TLR4 and TLR5 between non-OM and chronic OM patients, however the levels fell for CSOM patients. These studies indicate a correlation between reduced PRR function and severity of disease ( $\mathrm{Si}$ et al., 2014).

This lack of functionality in PRR signalling and subsequent protective innate immune responses in OM-prone individuals is likely due to polymorphisms in candidate genes related to innate and adaptive immunity. Children identified with TLR2 and TLR4 polymorphisms exhibit disrupted innate immune responses that increase their susceptibility to OM (Hafren et al., 2015; Toivonen et al., 2017). Genetic polymorphisms in Mannose-binding lectin and TLR2,3,4,7 and 8 can promote or protect children from the risk of respiratory infections and AOM (Toivonen et al., 2017) indicating that we do not fully understand the mechanisms of innate immunity influenced by gene polymorphisms.

Allelic association studies have identified polymorphisms related to the development of OM in genes encoding TLR4 receptors, IL-6, IL-10 and TNF- $\alpha$ (Emonts et al., 2007), mannose-binding lectins (Wiertsema et al., 2006), surfactant (Ramet et al., 2001), and Mucin gene MUC5AC (Ubell et al., 2010) [for review see (Mittal et al., 2014a; Lin et al., 2017; Geng et al., 2019)]. TLR4 locus polymorphisms have also been examined in patients with RAOM or COME and demonstrated a role for TLR4 in the regulation of the innate immune response. The inability of this study to replicate the association of a previously unrecognised TLR4 haplotype in two independent Finnish cohorts with UK or 2 US cohorts emphasises the potentially heterogenous nature of $\mathrm{OM}$ and the complexity of environmental and host factors that may modulate overall susceptibility to OM (Hafren et al., 2015; Einarsdottir et al., 2016). Polymorphism IL-1 $\beta+3953$ is associated with more severe presentations of $\mathrm{AOM}$ and has been associated with higher risk of severe inflammation post-AOM infection (McCormick et al., 2011). Recently, the potential impact of cohort heterogeneity and the complexity of environmental and host factors on OM development has been reviewed for a unique "stringentlydefined otitis-prone" population, where microbial confirmation of AOM through tympanocentesis was undertaken. The children in this cohort demonstrate a wide range of dysfunctional innate and adaptive immune responses that increase their vulnerability to upper respiratory tract infections and OM (Pichichero, 2020).

\section{CONCLUSION}

The middle ear clearly demonstrates the structural and functional features of a mucosal immune site, that for some children, results in increased susceptibility to recurrent or chronic OM. Investigations using a range of animal models (chinchilla, rat, mouse) and particularly genetically modified knockout mice, continue to improve our insight and 
understanding of activation and regulation of the host-microbial interactions within the middle ear in response to a variety of pathogens. The cellular immune apparatus within the middle ear can mount a rapid innate immune response to invading pathogens. Ongoing investigation and characterisation of the innate and adaptive immune responses of the middle ear mucosal tissues using clinical studies and animal models will elucidate this region's response to individual and multiple otopathogen infections, and the host factors that influence OM disease progression or clearance and response to vaccination. Some pathogens, such as NTHi can activate multiple, overlapping induction pathways resulting in innate immune system upregulation. Co-infection with multiple pathogens can also influence the host response. It is increasingly recognised that genetic polymorphisms, the level of expression of key regulatory molecules for the innate immune response and environmental factors such as pathogen load may impair innate immune system function and substantially increase the risk of predisposition of some children to more frequent or severe OM. Future studies need to explore the genetic and environmental interrelationships of these polymorphisms and their impact on predisposition or

\section{REFERENCES}

Abdel-Razek, O., Ni, L., Yang, F., and Wang, G. (2019). Innate Immunity of Surfactant Protein A in Experimental Otitis Media. Innate Immun. 25 (7), 391400. doi: 10.1177/1753425919866006

Armbruster, C. E., Hong, W., Pang, B., Weimer, K. E., Juneau, R. A., Turner, J., et al (2010). Indirect Pathogenicity of Haemophilus influenzae and Moraxella catarrhalis in Polymicrobial Otitis Media Occurs via Interspecies Quorum Signaling. mBio 1 (3), e00102-10. doi: 10.1128/mBio.00102-10

Bakaletz, L. O. (2010). Immunopathogenesis of Polymicrobial Otitis Media. J. Leukoc. Biol. 87 (2), 213-222. doi: 10.1189/jlb.0709518

Bakaletz, L. O. (2012). Bacterial Biofilms in the Upper Airway - Evidence for Role in Pathology and Implications for Treatment of Otitis Media. Paediatr. Respir. Rev. 13 (3), 154-159. doi: 10.1016/j.prrv.2012.03.001

Bakaletz, L. O., Murwin, D. M., and Billy, J. M. (1995). Adenovirus Serotype 1 Does Not Act Synergistically With Moraxella (Branhamella) Catarrhalis to Induce Otitis Media in the Chinchilla. Infect. Immun. 63 (10), 4188-4190. doi: 10.1128/iai.63.10.4188-4190.1995

Batoni, G., Maisetta, G., and Esin, S. (2021). Therapeutic Potential of Antimicrobial Peptides in Polymicrobial Biofilm-Associated Infections. Int. J. Mol. Sci. 22 (2), ijms22020482. doi: 10.3390/ijms22020482

Bergenfelz, C., and Hakansson, A. P. (2017). Streptococcus Pneumoniae Otitis Media Pathogenesis and How It Informs Our Understanding of Vaccine Strategies. Curr. Otorhinolaryngol. Rep. 5 (2), 115-124. doi: 10.1007/s40136017-0152-6

Bhutta, M. F. (2012). Mouse Models of Otitis Media: Strengths and Limitations. Otolaryngol. Head Neck Surg. 147 (4), 611-614. doi: 10.1177/0194599812449986

Bhutta, M. F., Thornton, R. B., Kirkham, L. S., Kerschner, J. E., and Cheeseman, M. T. (2017). Understanding the Aetiology and Resolution of Chronic Otitis Media From Animal and Human Studies. Dis. Model Mech. 10 (11), 12891300. doi: $10.1242 / \mathrm{dmm} .029983$

Binks, M. J., Cheng, A. C., Smith-Vaughan, H., Sloots, T., Nissen, M., Whiley, D., et al (2011). Viral-Bacterial Co-Infection in Australian Indigenous Children With Acute Otitis Media. BMC Infect. Dis. 11, 161. doi: 10.1186/1471-2334-11161

Bluestone, C. D., and Doyle, W. J. (1988). Anatomy and Physiology of Eustachian Tube and Middle Ear Related to Otitis Media. J. Allergy Clin. Immunol. 81 (5 Pt 2), 997-1003. doi: 10.1016/0091-6749(88)90168-6

Borghini, L., Lu, J., Hibberd, M., and Davila, S. (2018). Variation in Genome-Wide NF-kappaB RELA Binding Sites Upon Microbial Stimuli and Identification of a susceptibility to $\mathrm{OM}$ and its severity. Next generation sequencing and large, well-phenotyped populations from multiple regions will expand the applicability of these data to support development of new treatment strategies that may enhance innate immunity such as monophosphoryl lipid A (MPL) studies in mice (Iwasaki et al., 2017), $\beta$-defensin 2 and probiotics or alter the activation of the innate immune responses to reduce inflammation and chronic OM pathogenesis.

\section{AUTHOR CONTRIBUTIONS}

All authors contributed to the concept and writing of this review and agree to publication.

\section{ACKNOWLEDGMENTS}

Susan Stone: Sue-Stone.com for Figure 1 artwork.
Virus Response Profile. J. Immunol. 201 (4), 1295-1305. doi: 10.4049/ jimmunol.1800246

Brockson, M. E., Novotny, L. A., Jurcisek, J. A., McGillivary, G., Bowers, M. R., and Bakaletz, L. O. (2012). Respiratory Syncytial Virus Promotes Moraxella Catarrhalis-Induced Ascending Experimental Otitis Media. PloS One 7 (6), e40088. doi: 10.1371/journal.pone.0040088

Buchman, C. A., Doyle, W. J., Skoner, D., Fireman, P., and Gwaltney, J. M. (1994). Otologic Manifestations of Experimental Rhinovirus Infection. Laryngoscope 104 (10), 1295-1299. doi: 10.1288/00005537-199410000-00021

Carson, J. L., Collier, A. M., and Hu, S. S. (1985). Acquired Ciliary Defects in Nasa Epithelium of Children With Acute Viral Upper Respiratory Infections. $N$. Engl. J. Med. 312 (8), 463-468. doi: 10.1056/NEJM198502213120802

Chong, L. Y., Head, K., Webster, K. E., Daw, J., Richmond, P., Snelling, T., et al (2021). Topical Versus Systemic Antibiotics for Chronic Suppurative Otitis Media. Cochrane Database Syst. Rev. 2:CD013053. doi: 10.1002/ 14651858.CD013053.pub2

Chonmaitree, T., and Heikkinen, T. (2000). Viruses and Acute Otitis Media. Pediatr. Infect. Dis. J. 19 (10), 1005-1007. doi: 10.1097/00006454-200010000 00013

Chonmaitree, T., and Henrickson, K. J. (2000). Detection of Respiratory Viruses in the Middle Ear Fluids of Children With Acute Otitis Media by Multiplex Reverse Transcription:Polymerase Chain Reaction Assay. Pediatr. Infect. Dis. J. 19 (3), 258-260. doi: 10.1097/00006454-200003000-00020

Chonmaitree, T., Revai, K., Grady, J. J., Clos, A., Patel, J. A., Nair, S., et al (2008). Viral Upper Respiratory Tract Infection and Otitis Media Complication in Young Children. Clin. Infect. Dis. 46 (6), 815-823. doi: 10.1086/528685

Chonmaitree, T., Trujillo, R., Jennings, K., Alvarez-Fernandez, P., Patel, J. A., Loeffelholz, M. J., et al (2016). Acute Otitis Media and Other Complications of Viral Respiratory Infection. Pediatrics 137 (4), e20153555. doi: 10.1542/ peds.2015-3555

Chung, J. H., Lee, S. H., Woo, S. Y., Kim, S. W., and Cho, Y. S. (2016). Prevalence and Associated Factors of Chronic Suppurative Otitis Media: Data From the Korea National Health and Nutrition Examination Surve-2012. Laryngoscope 126 (10), 2351-2357. doi: 10.1002/lary.25981

Coates, H., Thornton, R., Langlands, J., Filion, P., Keil, A. D., Vijayasekaran, S. et al. (2008). The Role of Chronic Infection in Children With Otitis Media With Effusion: Evidence for Intracellular Persistence of Bacteria. Otolaryngol. Head Neck Surg. 138 (6), 778-781. doi: 10.1016/j.otohns.2007.02.009

Corscadden, K. J., Kirkham, L. A., Thornton, R. B., Vijayasekaran, S., Coates, H. L., Richmond, P. C., et al (2013). High Pneumococcal Serotype Specific IgG, IgG1 and IgG2 Levels in Serum and the Middle Ear of Children With Recurrent 
Acute Otitis Media Receiving Ventilation Tubes. Vaccine 31 (10), 1393-1399. doi: $10.1016 /$ j.vaccine.2012.12.078

Doyle, W. J., Skoner, D. P., Hayden, F., Buchman, C. A., Seroky, J. T., and Fireman, P. (1994). Nasal and Otologic Effects of Experimental Influenza A Virus Infection. Ann. Otol. Rhinol. Laryngol. 103 (1), 59-69. doi: 10.1177/ 000348949410300111

Einarsdottir, E., Hafren, L., Leinonen, E., Bhutta, M. F., Kentala, E., Kere, J., et al (2016). Genome-Wide Association Analysis Reveals Variants on Chromosome 19 That Contribute to Childhood Risk of Chronic Otitis Media With Effusion. Sci. Rep. 6, 33240. doi: 10.1038/srep33240

Emonts, M., Veenhoven, R. H., Wiertsema, S. P., Houwing-Duistermaat, J. J., Walraven, V., de Groot, R., et al (2007). Genetic Polymorphisms in Immunoresponse Genes TNFA, IL6, IL10, and TLR4 are Associated With Recurrent Acute Otitis Media. Pediatrics 120 (4), 814-823. doi: 10.1542/ peds.2007-0524

Enoksson, F., Ruiz Rodriguez, A., Peno, C., Balcazar Lopez, C., Tjernstrom, F., Bogaert, D., et al (2020). Niche- and Gender-Dependent Immune Reactions in Relation to the Microbiota Profile in Pediatric Patients With Otitis Media With Effusion. Infect. Immun. 88 (10), e00147-20. doi: 10.1128/IAI.00147-20

Evans, C. M., and Koo, J. S. (2009). Airway Mucus: The Good, the Bad, the Sticky. Pharmacol. Ther. 121 (3), 332-348. doi: 10.1016/j.pharmthera.2008.11.001

Forseni, M., Hansson, G. K., Bagger-Sjoback, D., and Hultcrantz, M. (1999). Infiltration of Immunocompetent Cells in the Middle Ear During Acute Otitis Media: A Temporal Study. Am. J. Otol. 20 (2), 152-157. Available at: https:// www.ncbi.nlm.nih.gov/pubmed/10100514

Geng, R., Wang, Q., Chen, E., and Zheng, Q. Y. (2019). Current Understanding of Host Genetics of Otitis Media. Front. Genet. 10, 1395. doi: 10.3389/ fgene.2019.01395

Giebink, G. S., Ripley, M. L., and Wright, P. F. (1987). Eustachian Tube Histopathology During Experimental Influenza A Virus Infection in the Chinchilla. Ann. Otol. Rhinol. Laryngol. 96 (2 Pt 1), 199-206. doi: 10.1177/ 000348948709600212

Giebink, G. S., and Wright, P. F. (1983). Different Virulence of Influenza A Virus Strains and Susceptibility to Pneumococcal Otitis Media in Chinchillas. Infect. Immun. 41 (3), 913-920. doi: 10.1128/iai.41.3.913-920.1983

Granath, A. (2017). Recurrent Acute Otitis Media: What Are the Options for Treatment and Prevention? Curr. Otorhinolaryngol. Rep. 5 (2), 93-100. doi: 10.1007/s40136-017-0151-7

Hafren, L., Einarsdottir, E., Kentala, E., Hammaren-Malmi, S., Bhutta, M. F., MacArthur, C. J., et al (2015). Predisposition to Childhood Otitis Media and Genetic Polymorphisms Within the Toll-Like Receptor 4 (TLR4) Locus. PloS One 10 (7), e0132551. doi: 10.1371/journal.pone.0132551

Hall-Stoodley, L., Hu, F. Z., Gieseke, A., Nistico, L., Nguyen, D., Hayes, J., et al (2006). Direct Detection of Bacterial Biofilms on the Middle-Ear Mucosa of Children With Chronic Otitis Media. JAMA 296 (2), 202-211. doi: 10.1001/ jama.296.2.202

Heikkinen, T. (2000). The Role of Respiratory Viruses in Otitis Media. Vaccine 19 Suppl 1, S51-S55. doi: 10.1016/s0264-410x(00)00278-4

Heikkinen, T., and Chonmaitree, T. (2000). Increasing Importance of Viruses in Acute Otitis Media. Ann. Med. 32 (3), 157-163. doi: 10.3109/ 07853890008998822

Heikkinen, T., and Chonmaitree, T. (2003). Importance of Respiratory Viruses in Acute Otitis Media. Clin. Microbiol. Rev. 16 (2), 230-241. doi: 10.1128/ CMR.16.2.230-241.2003

Heikkinen, T., Thint, M., and Chonmaitree, T. (1999). Prevalence of Various Respiratory Viruses in the Middle Ear During Acute Otitis Media. N. Engl. J. Med. 340 (4), 260-264. doi: 10.1056/NEJM199901283400402

Hernandez, M., Leichtle, A., Pak, K., Ebmeyer, J., Euteneuer, S., Obonyo, M., et al (2008). Myeloid Differentiation Primary Response Gene 88 is Required for the Resolution of Otitis Media. J. Infect. Dis. 198 (12), 1862-1869. doi: 10.1086/ 593213

Hernandez, M., Leichtle, A., Pak, K., Webster, N. J., Wasserman, S. I., and Ryan, A. F. (2015). The Transcriptome of a Complete Episode of Acute Otitis Media. BMC Genomics 16, 259. doi: 10.1186/s12864-015-1475-7

Holder, R. C., Kirse, D. J., Evans, A. K., Peters, T. R., Poehling, K. A., Swords, W. E., et al (2012). One Third of Middle Ear Effusions From Children Undergoing Tympanostomy Tube Placement had Multiple Bacterial Pathogens. BMC Pediatr. 12, 87. doi: 10.1186/1471-2431-12-87
Huang, Y., Wang, Z., Jin, C., Wang, L., Zhang, X., Xu, W., et al (2016). TLR2 Promotes Macrophage Recruitment and Streptococcus Pneumoniae Clearance During Mouse Otitis Media. Pediatr. Res. 80 (6), 886-893. doi: 10.1038/ pr.2016.154

Ichimiya, I., Kawauchi, H., and Mogi, G. (1990). Analysis of Immunocompetent Cells in the Middle Ear Mucosa. Arch. Otolaryngol. Head Neck Surg. 116 (3), 324-330. doi: 10.1001/archotol.1990.01870030088015

Ichimiya, I., Kurono, Y., and Mogi, G. (1997). Immunological Potential of the Tympanic Membrane. Observation Under Normal and Inflammatory Conditions. Am. J. Otolaryngol. 18 (3), 165-172. doi: 10.1016/s0196-0709 (97)90077-6

Iwasaki, T., Hirano, T., Kodama, S., Kadowaki, Y., Moriyama, M., Kawano, T., et al (2017). Monophosphoryl Lipid A Enhances Nontypeable Haemophilus Influenzae-Specific Mucosal and Systemic Immune Responses by Intranasal Immunization. Int. J. Pediatr. Otorhinolaryngol. 97, 5-12. doi: 10.1016/ j.ijporl.2017.03.018

Jecker, P., Pabst, R., and Westermann, J. (1996). The Mucosa of the Middle Ear and Eustachian Tube in the Young Rat: Number of Granulocytes, Macrophages, Dendritic Cells, NK Cells and T and B Lymphocytes in Healthy Animals and During Otitis Media. Acta Otolaryngol. 116 (3), 443450. doi: 10.3109/00016489609137871

Jecker, P., Pabst, R., and Westermann, J. (2001). Proliferating Macrophages, Dendritic Cells, Natural Killer Cells, T and B Lymphocytes in the Middle Ear and Eustachian Tube Mucosa During Experimental Acute Otitis Media in the Rat. Clin. Exp. Immunol. 126 (3), 421-425. doi: 10.1046/j.13652249.2001.01543.x

Jervis-Bardy, J., Leong, L. E. X., Papanicolas, L. E., Ivey, K. L., Chawla, S., Woods, C. M., et al (2019). Examining the Evidence for an Adult Healthy Middle Ear Microbiome. mSphere 4 (5), e00456-19. doi: 10.1128/mSphere.00456-19

Johnston, J., Hoggard, M., Biswas, K., Astudillo-Garcia, C., Radcliff, F. J., Mahadevan, M., et al (2019). Pathogen Reservoir Hypothesis Investigated by Analyses of the Adenotonsillar and Middle Ear Microbiota. Int. J. Pediatr. Otorhinolaryngol. 118, 103-109. doi: 10.1016/j.ijporl.2018.12.030

Juneau, R. A., Pang, B., Weimer, K. E., Armbruster, C. E., and Swords, W. E. (2011). Nontypeable Haemophilus Influenzae Initiates Formation of Neutrophil Extracellular Traps. Infect. Immun. 79 (1), 431-438. doi: 10.1128/ IAI.00660-10

Kalu, S. U., Ataya, R. S., McCormick, D. P., Patel, J. A., Revai, K., and Chonmaitree, T. (2011). Clinical Spectrum of Acute Otitis Media Complicating Upper Respiratory Tract Viral Infection. Pediatr. Infect. Dis. J. 30 (2), 95-99. doi: 10.1097/INF.0b013e3181f253d5

Kaur, R., Casey, J., and Pichichero, M. (2015). Cytokine, Chemokine, and TollLike Receptor Expression in Middle Ear Fluids of Children With Acute Otitis Media. Laryngoscope 125 (1), E39-E44. doi: 10.1002/lary.24920

Kaur, R., Morris, M., and Pichichero, M. E. (2017). Epidemiology of Acute Otitis Media in the Postpneumococcal Conjugate Vaccine Era. Pediatrics 140 (3), pii: peds.2017-0181.e20174067. doi: 10.1542/peds.2017-0181

Kawai, T., and Akira, S. (2009). The Roles of TLRs, RLRs and NLRs in Pathogen Recognition. Int. Immunol. 21 (4), 317-337. doi: 10.1093/intimm/dxp017

Kim, S. H., Cha, S. H., Kim, Y. I., Byun, J. Y., Park, M. S., and Yeo, S. G. (2015). Age-Dependent Changes in Pattern Recognition Receptor and Cytokine mRNA Expression in Children With Otitis Media With Effusion. Int. J. Pediatr. Otorhinolaryngol. 79 (2), 229-234. doi: 10.1016/j.ijporl.2014.12.015

Kim, Y. J., Cha, S. H., Lee, H. Y., Lee, S. K., Chung, H. Y., Yeo, J. H., et al (2014). Decreased Pattern-Recognition Receptor-Mediated Cytokine mRNA Expression in Obese Children With Otitis Media With Effusion. Clin. Exp. Otorhinolaryngol. 7 (1), 7-12. doi: 10.3342/ceo.2014.7.1.7

Kim, M. G., Park, D. C., Shim, J. S., Jung, H., Park, M. S., Kim, Y. I., et al (2010). TLR-9, NOD-1, NOD-2, RIG-I and Immunoglobulins in Recurrent Otitis Media With Effusion. Int. J. Pediatr. Otorhinolaryngol. 74 (12), 1425-1429. doi: 10.1016/j.ijporl.2010.09.026

Komori, M., Nakamura, Y., Ping, J., Feng, L., Toyama, K., Kim, Y., et al (2011). Pneumococcal Peptidoglycan-Polysaccharides Regulate Toll-Like Receptor 2 in the Mouse Middle Ear Epithelial Cells. Pediatr. Res. 69 (2), 101-105. doi: 10.1203/PDR.0b013e3182055237

Kong, K., and Coates, H. L. (2009). Natural History, Definitions, Risk Factors and Burden of Otitis Media. Med. J. Aust. 191 (S9), S39-S43. doi: 10.5694/j.13265377.2009.tb02925.x 
Krekorian, T. D., Keithley, E. M., Fierer, J., and Harris, J. P. (1991). Type B Haemophilus Influenzae-Induced Otitis Media in the Mouse. Laryngoscope 101 (6 Pt 1), 648-656. doi: 10.1288/00005537-199106000-00013

Krishnamurthy, A., McGrath, J., Cripps, A. W., and Kyd, J. M. (2009). The Incidence of Streptococcus Pneumoniae Otitis Media is Affected by the Polymicrobial Environment Particularly Moraxella Catarrhalis in a Mouse Nasal Colonisation Model. Microbes Infect. 11 (5), 545-553. doi: 10.1016/ j.micinf.2009.03.001

Kumar, S., Ingle, H., Prasad, D. V., and Kumar, H. (2013). Recognition of Bacterial Infection by Innate Immune Sensors. Crit. Rev. Microbiol. 39 (3), 229-246. doi: 10.3109/1040841X.2012.706249

Kumar, H., Kawai, T., and Akira, S. (2011). Pathogen Recognition by the Innate Immune System. Int. Rev. Immunol. 30 (1), 16-34. doi: 10.3109/ 08830185.2010.529976

Kurabi, A., Pak, K., Ryan, A. F., and Wasserman, S. I. (2016). Innate Immunity: Orchestrating Inflammation and Resolution of Otitis Media. Curr. Allergy Asthma Rep. 16 (1), 6. doi: 10.1007/s11882-015-0585-2

Kurono, Y., Shigemi, H., Kodama, S., and Mogi, G. (1996). The Role of Adenoids in Nasopharyngeal Colonization With Nontypeable Haemophilus Influenzae. Acta Otolaryngol. Suppl. 523, 147-149. Available at: https://www.ncbi.nlm.nih. gov/pubmed/9082764

Kweon, S. M., Wang, B., Rixter, D., Lim, J. H., Koga, T., Ishinaga, H., et al (2006). Synergistic Activation of NF-kappaB by Nontypeable H. Influenzae and S. Pneumoniae is Mediated by CK2, IKKbeta-IkappaBalpha, and P38 MAPK. Biochem. Biophys. Res. Commun. 351 (2), 368-375. doi: 10.1016/j.bbrc.2006.10.052

Leach, A. J., Morris, P. S., Mathews, J. D.Chronic Otitis Media Intervention Trial One, g (2008). Compared to Placebo, Long-Term Antibiotics Resolve Otitis Media With Effusion (OME) and Prevent Acute Otitis Media With Perforation (AOMwiP) in a High-Risk Population: A Randomized Controlled Trial. BMC Pediatr. 8:23. doi: 10.1186/1471-2431-8-23

Lee, Y. W., Chung, Y., Juhn, S. K., Kim, Y., and Lin, J. (2011). Activation of the Transforming Growth Factor Beta Pathway in Bacterial Otitis Media. Ann. Otol. Rhinol. Laryngol. 120 (3), 204-213. doi: 10.1177/000348941112000310

Lee, J., Leichtle, A., Zuckerman, E., Pak, K., Spriggs, M., Wasserman, S. I., et al (2019). NOD1/NOD2-Mediated Recognition of non-Typeable Haemophilus Influenzae Activates Innate Immunity During Otitis Media. Innate Immun. 25 (8), 503-512. doi: 10.1177/1753425919872266

Lee, K., Shin, S. Y., Kim, K., Lim, S. S., Hahm, K. S., and Kim, Y. (2004). Antibiotic Activity and Structural Analysis of the Scorpion-Derived Antimicrobial Peptide IsCT and its Analogs. Biochem. Biophys. Res. Commun. 323 (2), 712-719. doi: 10.1016/j.bbrc.2004.08.144

Lee, H. Y., Takeshita, T., Shimada, J., Akopyan, A., Woo, J. I., Pan, H., et al (2008). Induction of Beta Defensin 2 by NTHi Requires TLR2 Mediated MyD88 and IRAK-TRAF6-P38mapk Signaling Pathway in Human Middle Ear Epithelial Cells. BMC Infect. Dis. 8:87. doi: 10.1186/1471-2334-8-87

Leichtle, A., Hernandez, M., Lee, J., Pak, K., Webster, N. J., Wollenberg, B., et al (2012). The Role of DNA Sensing and Innate Immune Receptor TLR9 in Otitis Media. Innate Immun. 18 (1), 3-13. doi: 10.1177/1753425910393539

Leichtle, A., Hernandez, M., Pak, K., Yamasaki, K., Cheng, C. F., Webster, N. J., et al (2009). TLR4-Mediated Induction of TLR2 Signaling is Critical in the Pathogenesis and Resolution of Otitis Media. Innate Immun. 15 (4), 205-215. doi: $10.1177 / 1753425909103170$

Leichtle, A., Lai, Y., Wollenberg, B., Wasserman, S. I., and Ryan, A. F. (2011). Innate Signaling in Otitis Media: Pathogenesis and Recovery. Curr. Allergy Asthma Rep. 11 (1), 78-84. doi: 10.1007/s11882-010-0158-3

Li, P., and Chang, M. (2021). Roles of PRR-Mediated Signaling Pathways in the Regulation of Oxidative Stress and Inflammatory Diseases. Int. J. Mol. Sci. 22 (14), ijms22147688. doi: 10.3390/ijms22147688

Lieberthal, A. S., Carroll, A. E., Chonmaitree, T., Ganiats, T. G., Hoberman, A., Jackson, M. A., et al (2013). The Diagnosis and Management of Acute Otitis Media. Pediatrics 131 (3), e964-e999. doi: 10.1542/peds.2012-3488

Li, J. D., Hermansson, A., Ryan, A. F., Bakaletz, L. O., Brown, S. D., Cheeseman, M. T., et al (2013). Panel 4: Recent Advances in Otitis Media in Molecular Biology, Biochemistry, Genetics, and Animal Models. Otolaryngol. Head Neck Surg. 148 (4 Suppl), E52-E63. doi: 10.1177/0194599813479772

Lim, D. J. (1976). Functional Morphology of the Mucosa of the Middle Ear and Eustachian Tube. Ann. Otol. Rhinol. Laryngol. 85 (2 Suppl 25 Pt 2), 36-43. doi: $10.1177 / 00034894760850 S 209$
Lim, D. J. (1979). Normal and Pathological Mucosa of the Middle Ear and Eustachian Tube. Clin. Otolaryngol. Allied Sci. 4 (3), 213-232. doi: 10.1111/ j.1365-2273.1979.tb01888.x

Lim, D. J., Chun, Y. M., Lee, H. Y., Moon, S. K., Chang, K. H., Li, J. D., et al (2000). Cell Biology of Tubotympanum in Relation to Pathogenesis of Otitis Media - a Review. Vaccine 19 (Suppl 1), S17-S25. doi: 10.1016/s0264-410x(00)00273-5

Lim, E. J., Lee, S. H., Lee, J. G., Kim, J. R., Yun, S. S., Baek, S. H., et al (2007). TollLike Receptor 9 Dependent Activation of MAPK and NF-kB is Required for the CpG ODN-Induced Matrix Metalloproteinase-9 Expression. Exp. Mol. Med. 39 (2), 239-245. doi: 10.1038/emm.2007.27

Linden, S. K., Sutton, P., Karlsson, N. G., Korolik, V., and McGuckin, M. A. (2008). Mucins in the Mucosal Barrier to Infection. Mucosal Immunol. 1 (3), 183-197. doi: $10.1038 / \mathrm{mi} .2008 .5$

Lin, J., Hafren, L., Kerschner, J., Li, J. D., Brown, S., Zheng, Q. Y., et al (2017). Panel 3: Genetics and Precision Medicine of Otitis Media. Otolaryngol. Head Neck Surg. 156 (4_suppl), S41-S50. doi: 10.1177/0194599816685559

Liu, K., Chen, L., Kaur, R., and Pichichero, M. E. (2013). Transcriptome Signature in Young Children With Acute Otitis Media Due to non-Typeable Haemophilus Influenzae. Int. Immunol. 25 (6), 353-361. doi: 10.1093/ intimm/dxs 154

Lysenko, E. S., Ratner, A. J., Nelson, A. L., and Weiser, J. N. (2005). The Role of Innate Immune Responses in the Outcome of Interspecies Competition for Colonization of Mucosal Surfaces. PloS Pathog. 1 (1), e1. doi: 10.1371/ journal.ppat.0010001

MacArthur, C. J., Hefeneider, S. H., Kempton, J. B., Parrish, S. K., McCoy, S. L., and Trune, D. R. (2006). Evaluation of the Mouse Model for Acute Otitis Media. Hear. Res. 219 (1-2), 12-23. doi: 10.1016/j.heares.2006.05.012

MacArthur, C. J., Pillers, D. A., Pang, J., Kempton, J. B., and Trune, D. R. (2011). Altered Expression of Middle and Inner Ear Cytokines in Mouse Otitis Media. Laryngoscope 121 (2), 365-371. doi: 10.1002/lary.21349

Ma, Y. K., Chen, Y. B., and Li, P. (2018). Quercetin Inhibits NTHi-Triggered CXCR4 Activation Through Suppressing IKKalpha/NF-kappaB and MAPK Signaling Pathways in Otitis Media. Int. J. Mol. Med. 42 (1), 248-258. doi: $10.3892 / \mathrm{ijmm} .2018 .3577$

Mandel, E. M., Doyle, W. J., Winther, B., and Alper, C. M. (2008). The Incidence, Prevalence and Burden of $\mathrm{OM}$ in Unselected Children Aged 1-8 Years Followed by Weekly Otoscopy Through the "Common Cold" Season. Int. J. Pediatr. Otorhinolaryngol. 72 (4), 491-499. doi: 10.1016/j.ijporl.2007.12.008

Marsh, R. L., Aho, C., Beissbarth, J., Bialasiewicz, S., Binks, M., Cervin, A., et al (2020). Panel 4: Recent Advances in Understanding the Natural History of the Otitis Media Microbiome and its Response to Environmental Pressures. Int. J. Pediatr. Otorhinolaryngol. 130 (Suppl 1), 109836. doi: 10.1016/ j.ijporl.2019.109836

Martin, C., Karkas, A., and Prades, J. M. (2017). Tubotympanic System Functioning. Eur. Ann. Otorhinolaryngol. Head Neck Dis. 134 (3), 177-184. doi: 10.1016/j.anorl.2017.03.010

Massa, H. M., Lim, D. J., Kurono, Y., and Cripps, A. W. (2015). "Chapter 101: Middle Ear and Eustachian Tube Mucosal Immunology," in Mucosal Immunology. Eds. W. S. Jiri Mestecky, M. W. Russell, B. L. Kelsall, H. Cheroutre and B. N. Lambrecht (Cambridge: Academic press), 1923-1942. doi: 10.1016/B978-0-12-415847-4.00101-4

McBride, T. P., Doyle, W. J., Hayden, F. G., and Gwaltney, J. M.Jr. (1989). Alterations of the Eustachian Tube, Middle Ear, and Nose in Rhinovirus Infection. Arch. Otolaryngol. Head Neck Surg. 115 (9), 1054-1059. doi: 10.1001/archotol.1989.01860330044014

McCormick, D. P., Grady, J. J., Diego, A., Matalon, R., Revai, K., Patel, J. A., et al (2011). Acute Otitis Media Severity: Association With Cytokine Gene Polymorphisms and Other Risk Factors. Int. J. Pediatr. Otorhinolaryngol. 75 (5), 708-712. doi: 10.1016/j.ijporl.2011.02.021

McGillivary, G., Mason, K. M., Jurcisek, J. A., Peeples, M. E., and Bakaletz, L. O. (2009). Respiratory Syncytial Virus-Induced Dysregulation of Expression of a Mucosal Beta-Defensin Augments Colonization of the Upper Airway by nonTypeable Haemophilus Influenzae. Cell Microbiol. 11 (9), 1399-1408. doi: 10.1111/j.1462-5822.2009.01339.x

McGillivary, G., Ray, W. C., Bevins, C. L., Munson, R. S.Jr., and Bakaletz, L. O. (2007). A Member of the Cathelicidin Family of Antimicrobial Peptides is Produced in the Upper Airway of the Chinchilla and its mRNA Expression is 
Altered by Common Viral and Bacterial Co-Pathogens of Otitis Media. Mol. Immunol. 44 (9), 2446-2458. doi: 10.1016/j.molimm.2006.10.008

Medzhitov, R. (2007). Recognition of Microorganisms and Activation of the Immune Response. Nature 449 (7164), 819-826. doi: 10.1038/nature06246

Melvin, J. A., and Bomberger, J. M. (2016). Compromised Defenses: Exploitation of Epithelial Responses During Viral-Bacterial Co-Infection of the Respiratory Tract. PloS Pathog. 12 (9), e1005797. doi: 10.1371/journal.ppat.1005797

Mittal, R., Kodiyan, J., Gerring, R., Mathee, K., Li, J. D. , Grati, M., et al (2014b). Role of Innate Immunity in the Pathogenesis of Otitis Media. Int. J. Infect. Dis. 29, 259-267. doi: 10.1016/j.ijid.2014.10.015

Mittal, R., Robalino, G., Gerring, R., Chan, B., Yan, D. , Grati, M., et al (2014a). Immunity Genes and Susceptibility to Otitis Media: A Comprehensive Review. J. Genet. Genomics 41 (11), 567-581. doi: 10.1016/j.jgg.2014.10.003

Monasta, L., Ronfani, L., Marchetti, F., Montico, M., Vecchi Brumatti, L., Bavcar, A., et al (2012). Burden of Disease Caused by Otitis Media: Systematic Review and Global Estimates. PloS One 7 (4), e36226. doi: 10.1371/ journal.pone. 0036226

Moon, S. K., Woo, J. I., Lee, H. Y., Park, R., Shimada, J., Pan, H., et al (2007). TollLike Receptor 2-Dependent NF-kappaB Activation is Involved in Nontypeable Haemophilus Influenzae-Induced Monocyte Chemotactic Protein 1 UpRegulation in the Spiral Ligament Fibrocytes of the Inner Ear. Infect. Immun. 75 (7), 3361-3372. doi: 10.1128/IAI.01886-06

Moore, H. C., Jacoby, P., Taylor, A., Harnett, G., Bowman, J., Riley, T. V., et al (2010). The Interaction Between Respiratory Viruses and Pathogenic Bacteria in the Upper Respiratory Tract of Asymptomatic Aboriginal and nonAboriginal Children. Pediatr. Infect. Dis. J. 29 (6), 540-545. doi: 10.1097/ INF.0b013e3181d067cb

Murrah, K. A., Turner, R. L., Pang, B., Perez, A. C., Reimche, J. L., King, L. B., et al (2015). Replication of Type 5 Adenovirus Promotes Middle Ear Infection by Streptococcus Pneumoniae in the Chinchilla Model of Otitis Media. Pathog. Dis. 73 (2), 1-8. doi: 10.1111/2049-632X.12216

Ngo, C. C., Massa, H. M., Thornton, R. B., and Cripps, A. W. (2016). Predominant Bacteria Detected From the Middle Ear Fluid of Children Experiencing Otitis Media: A Systematic Review. PloS One 11 (3), e0150949. doi: 10.1371/ journal.pone.0150949

Nokso-Koivisto, J., Marom, T., and Chonmaitree, T. (2015). Importance of Viruses in Acute Otitis Media. Curr. Opin. Pediatr. 27 (1), 110-115. doi: 10.1097/MOP.0000000000000184

Novotny, L. A., Clements, J. D., Goodman, S. D., and Bakaletz, L. O. (2017). Transcutaneous Immunization With a Band-Aid Prevents Experimental Otitis Media in a Polymicrobial Model. Clin. Vaccine Immunol. 24 (6), CVI.00563-16. doi: 10.1128/CVI.00563-16

Palva, T., Tolvanen, E., Konttinen, Y. T., and Reitamo, S. (1981). Inflammatory Cells in the Middle Ear Mucosa in Cases of Chronic Otitis Media. Arch. Otolaryngol. 107 (9), 528-531. doi: 10.1001/archotol.1981.00790450004003

Parrish, J. M., Soni, M., and Mittal, R. (2019). Subversion of Host Immune Responses by Otopathogens During Otitis Media. J. Leukoc. Biol. 106 (4), 943956. doi: 10.1002/JLB.4RU0119-003R

Patel, J., Faden, H., Sharma, S., and Ogra, P. L. (1992). Effect of Respiratory Syncytial Virus on Adherence, Colonization and Immunity of non-Typable Haemophilus Influenzae: Implications for Otitis Media. Int. J. Pediatr. Otorhinolaryngol. 23 (1), 15-23. doi: 10.1016/0165-5876(92)90075-Z

Patel, J. A., Nair, S., Grady, J., Revai, K., Victor, S. Brasier, A. R., et al (2009a). Systemic Cytokine Response Profiles Associated With Respiratory VirusInduced Acute Otitis Media. Pediatr. Infect. Dis. J. 28 (5), 407-411. doi: 10.1097/INF.0b013e318194b7c6

Patel, J. A., Nair, S., Revai, K., Grady, J. , and Chonmaitree, T. (2009b). Nasopharyngeal Acute Phase Cytokines in Viral Upper Respiratory Infection: Impact on Acute Otitis Media in Children. Pediatr. Infect. Dis. J. 28 (11), 10021007. doi: 10.1097/INF.0b013e3181aa5b13

Pettigrew, M. M., Gent, J. F., Pyles, R. B., Miller, A. L., Nokso-Koivisto, J., and Chonmaitree, T. (2011). Viral-Bacterial Interactions and Risk of Acute Otitis Media Complicating Upper Respiratory Tract Infection. J. Clin. Microbiol. 49 (11), 3750-3755. doi: 10.1128/JCM.01186-11

Pichichero, M. E. (2020). Immunologic Dysfunction Contributes to the Otitis Prone Condition. J. Infect. 80 (6), 614-622. doi: 10.1016/j.jinf.2020.03.017

Preciado, D., Granath, A., Lin, J., Val, S., Kurabi, A., Johnston, N., et al (2017). Panel 8: Report on Recent Advances in Molecular and Cellular Biochemistry.
Otolaryngol. Head Neck Surg. 156 (4_suppl), S106-S113. doi: 10.1177/ 0194599816658290

Ramet, M., Lofgren, J., Alho, O. P., and Hallman, M. (2001). Surfactant Protein-A Gene Locus Associated With Recurrent Otitis Media. J. Pediatr. 138 (2), 266268. doi: $10.1067 / \mathrm{mpd} .2001 .110133$

Ratner, A. J., Lysenko, E. S., Paul, M. N., and Weiser, J. N. (2005). Synergistic Proinflammatory Responses Induced by Polymicrobial Colonization of Epithelial Surfaces. Proc. Natl. Acad. Sci. U.S.A. 102 (9), 3429-3434. doi: 10.1073/pnas.0500599102

Robledo-Avila, F. H., Ruiz-Rosado, J. D., Partida-Sanchez, S., and Brockman, K. L. (2020). A Bacterial Epigenetic Switch in Non-Typeable Haemophilus Influenzae Modifies Host Immune Response During Otitis Media. Front. Cell Infect. Microbiol. 10:512743. doi: 10.3389/fcimb.2020.512743

Rosenfeld, R. M., Shin, J. J., Schwartz, S. R., Coggins, R., Gagnon, L., Hackell, J. M., et al (2016). Clinical Practice Guideline: Otitis Media With Effusion (Update). Otolaryngol. Head Neck Surg. 154 (1 Suppl), S1-S41. doi: 10.1177/0194599815623467

Ruohola, A., Pettigrew, M. M., Lindholm, L., Jalava, J., Raisanen, K. S., Vainionpaa, R., et al (2013). Bacterial and Viral Interactions Within the Nasopharynx Contribute to the Risk of Acute Otitis Media. J. Infect. 66 (3), 247-254. doi: 10.1016/j.jinf.2012.12.002

Ryan, A. F., Nasamran, C. A., Pak, K., Draf, C., Fisch, K. M., Webster, N., et al (2020). Single-Cell Transcriptomes Reveal a Complex Cellular Landscape in the Middle Ear and Differential Capacities for Acute Response to Infection. Front. Genet. 11:358. doi: 10.3389/fgene.2020.00358

Sawada, S., Okutani, F., and Kobayashi, T. (2019). Comprehensive Detection of Respiratory Bacterial and Viral Pathogens in the Middle Ear Fluid and Nasopharynx of Pediatric Patients With Acute Otitis Media. Pediatr. Infect. Dis. J. 38 (12), 1199-1203. doi: 10.1097/INF.0000000000002486

Schachern, P. A., Kwon, G., Briles, D. E., Ferrieri, P., Juhn, S., Cureoglu, S., et al (2017). Neutrophil Extracellular Traps and Fibrin in Otitis Media: Analysis of Human and Chinchilla Temporal Bones. JAMA Otolaryngol. Head Neck Surg. 143 (10), 990-995. doi: 10.1001/jamaoto.2017.1320

Schenck, L. P., Surette, M. G., and Bowdish, D. M. (2016). Composition and Immunological Significance of the Upper Respiratory Tract Microbiota. FEBS Lett. 590 (21), 3705-3720. doi: 10.1002/1873-3468.12455

Schilder, A. G., Chonmaitree, T., Cripps, A. W., Rosenfeld, R. M., Casselbrant, M. L., Haggard, M. P., et al (2016). Otitis Media. Nat. Rev. Dis. Primers 2, 16063. doi: $10.1038 /$ nrdp. 2016.63

Seppanen, E. J., Thornton, R. B., Corscadden, K. J., Granland, C. M., Hibbert, J., Fuery, A., et al (2019). High Concentrations of Middle Ear Antimicrobial Peptides and Proteins and Proinflammatory Cytokines are Associated With Detection of Middle Ear Pathogens in Children With Recurrent Acute Otitis Media. PloS One 14 (12), e0227080. doi: 10.1371/journal.pone.0227080

Shakhnovich, E. A., King, S. J., and Weiser, J. N. (2002). Neuraminidase Expressed by Streptococcus Pneumoniae Desialylates the Lipopolysaccharide of Neisseria Meningitidis and Haemophilus Influenzae: A Paradigm for Interbacterial Competition Among Pathogens of the Human Respiratory Tract. Infect. Immun. 70 (12), 7161-7164. doi: 10.1128/IAI.70.12.7161-7164.2002

Shimada, J., Moon, S. K., Lee, H. Y., Takeshita, T., Pan, H., Woo, J. I., et al (2008). Lysozyme M Deficiency Leads to an Increased Susceptibility to Streptococcus Pneumoniae-Induced Otitis Media. BMC Infect. Dis. 8, 134. doi: 10.1186/14712334-8-134

Short, K. R., Diavatopoulos, D. A., Thornton, R., Pedersen, J., Strugnell, R. A., Wise, A. K., et al (2011). Influenza Virus Induces Bacterial and Nonbacterial Otitis Media. J. Infect. Dis. 204 (12), 1857-1865. doi: 10.1093/infdis/jir618

Short, K. R., Reading, P. C., Brown, L. E., Pedersen, J., Gilbertson, B., Job, E. R., et al (2013). Influenza-Induced Inflammation Drives Pneumococcal Otitis Media. Infect. Immun. 81 (3), 645-652. doi: 10.1128/IAI.01278-12

Si, Y., Zhang, Z. G., Chen, S. J., Zheng, Y. Q., Chen, Y. B., Liu, Y., et al (2014). Attenuated TLRs in Middle Ear Mucosa Contributes to Susceptibility of Chronic Suppurative Otitis Media. Hum. Immunol. 75 (8), 771-776. doi: 10.1016/j.humimm.2014.05.009

Skevaki, C., Pararas, M., Kostelidou, K., Tsakris, A., and Routsias, J. G. (2015). Single Nucleotide Polymorphisms of Toll-Like Receptors and Susceptibility to Infectious Diseases. Clin. Exp. Immunol. 180 (2), 165-177. doi: 10.1111/cei.12578

Song, J. J., Cho, J. G., Woo, J. S., Lee, H. M., Hwang, S. J., and Chae, S. W. (2009). Differential Expression of Toll-Like Receptors 2 and 4 in Rat Middle Ear. Int. J. Pediatr. Otorhinolaryngol. 73 (6), 821-824. doi: 10.1016/j.ijporl.2009.02.017 
Spoiala, E. L., Stanciu, G. D., Bild, V., Ababei, D. C., and Gavrilovici, C. (2021). From Evidence to Clinical Guidelines in Antibiotic Treatment in Acute Otitis Media in Children. Antibiotics (Basel) 10 (1), antibiotics10010052. doi: 10.3390/antibiotics10010052

Stockmann, C., Ampofo, K., Hersh, A. L., Carleton, S. T., Korgenski, K., Sheng, X., et al (2013). Seasonality of Acute Otitis Media and the Role of Respiratory Viral Activity in Children. Pediatr. Infect. Dis. J. 32 (4), 314-319. doi: 10.1097/ INF.0b013e31827d104e

Suenaga, S., Kodama, S., Ueyama, S., Suzuki, M., and Mogi, G. (2001). Mucosal Immunity of the Middle Ear: Analysis at the Single Cell Level. Laryngoscope 111 (2), 290-296. doi: 10.1097/00005537-200102000-00019

Suzuki, K., and Bakaletz, L. O. (1994). Synergistic Effect of Adenovirus Type 1 and Nontypeable Haemophilus Influenzae in a Chinchilla Model of Experimental Otitis Media. Infect. Immun. 62 (5), 1710-1718. doi: 10.1128/iai.62.5.17101718.1994

Tahar Aissa, J., and Hultcrantz, M. (2009). Acute Tympanic Membrane Perforations and the Early Immunological Response in Rats. Acta Otolaryngol. 129 (11), 1192-1197. doi: 10.3109/00016480802669552

Thornton, R. B., Rigby, P. J., Wiertsema, S. P., Filion, P., Langlands, J., Coates, H. L., et al (2011). Multi-Species Bacterial Biofilm and Intracellular Infection in Otitis Media. BMC Pediatr. 11 11, 94. doi: 10.1186/1471-2431-11-94

Thornton, R. B., Wiertsema, S. P., Kirkham, L. A., Rigby, P. J., Vijayasekaran, S., Coates, H. L., et al (2013). Neutrophil Extracellular Traps and Bacterial Biofilms in Middle Ear Effusion of Children With Recurrent Acute Otitis Media-a Potential Treatment Target. PloS One 8 (2), e53837. doi: 10.1371/ journal.pone.0053837

Toivonen, L., Vuononvirta, J., Mertsola, J., Waris, M., He, Q., and Peltola, V. (2017). Polymorphisms of Mannose-Binding Lectin and Toll-Like Receptors 2, 3, 4, 7 and 8 and the Risk of Respiratory Infections and Acute Otitis Media in Children. Pediatr. Infect. Dis. J. 36 (5), el14-e122. doi: 10.1097/INF.0000000000001479

Tong, H. H., Fisher, L. M., Kosunick, G. M., and DeMaria, T. F. (2000). Effect of Adenovirus Type 1 and Influenza A Virus on Streptococcus Pneumoniae Nasopharyngeal Colonization and Otitis Media in the Chinchilla. Ann. Otol. Rhinol. Laryngol. 109 (11), 1021-1027. doi: 10.1177/000348940010901106

Tong, H. H., Lambert, G., Li, Y. X., Thurman, J. M., Stahl, G. L., Douthitt, K., et al (2014). Deletion of the Complement C5a Receptor Alleviates the Severity of Acute Pneumococcal Otitis Media Following Influenza A Virus Infection in Mice. PloS One 9 (4), e95160. doi: 10.1371/journal.pone.0095160

Tong, H. H., Long, J. P., Li, D., and DeMaria, T. F. (2004). Alteration of Gene Expression in Human Middle Ear Epithelial Cells Induced by Influenza A Virus and its Implication for the Pathogenesis of Otitis Media. Microb. Pathog. 37 (4), 193-204. doi: 10.1016/j.micpath.2004.06.012

Tong, H. H., Long, J. P., Shannon, P. A., and DeMaria, T. F. (2003). Expression of Cytokine and Chemokine Genes by Human Middle Ear Epithelial Cells Induced by Influenza A Virus and Streptococcus Pneumoniae Opacity Variants. Infect. Immun. 71 (8), 4289-4296. doi: 10.1128/IAI.71.8.42894296.2003

Trune, D. R., Kempton, B., Hausman, F. A., Larrain, B. E., and MacArthur, C. J. (2015). Correlative mRNA and Protein Expression of Middle and Inner Ear Inflammatory Cytokines During Mouse Acute Otitis Media. Hear. Res. 326, 49-58. doi: 10.1016/j.heares.2015.04.006

Trune, D. R., and Zheng, Q. Y. (2009). Mouse Models for Human Otitis Media. Brain Res. 1277, 90-103. doi: 10.1016/j.brainres.2009.02.047

Tsukita, S., Yamazaki, Y., Katsuno, T., Tamura, A., and Tsukita, S. (2008). Tight Junction-Based Epithelial Microenvironment and Cell Proliferation. Oncogene 27 (55), 6930-6938. doi: 10.1038/onc.2008.344
Tyrer, H. E., Crompton, M., and Bhutta, M. F. (2013). What Have We Learned From Murine Models of Otitis Media? Curr. Allergy Asthma Rep. 13 (5), 501511. doi: $10.1007 / \mathrm{s} 11882-013-0360-1$

Ubell, M. L., Khampang, P., and Kerschner, J. E. (2010). Mucin Gene Polymorphisms in Otitis Media Patients. Laryngoscope 120 (1), 132-138. doi: $10.1002 /$ lary.2068

Underwood, M., and Bakaletz, L. (2011). Innate Immunity and the Role of Defensins in Otitis Media. Curr. Allergy Asthma Rep. 11 (6), 499-507. doi: 10.1007/s11882-011-0223-6

Val, S., Poley, M., Anna, K., Nino, G., Brown, K., Perez-Losada, M., et al (2018). Characterization of Mucoid and Serous Middle Ear Effusions From Patients With Chronic Otitis Media: Implication of Different Biological Mechanisms? Pediatr. Res. 84 (2), 296-305. doi: 10.1038/s41390-018-0060-6

Wiertsema, S. P., Herpers, B. L., Veenhoven, R. H., Salimans, M. M., Ruven, H. J., Sanders, E. A., et al (2006). Functional Polymorphisms in the Mannan-Binding Lectin 2 Gene: Effect on MBL Levels and Otitis Media. J. Allergy Clin. Immunol. 117 (6), 1344-1350. doi: 10.1016/j.jaci.2006.01.031

Woo, J. I., Oh, S., Webster, P., Lee, Y. J., Lim, D. J., and Moon, S. K. (2014). NOD2/ RICK-Dependent Beta-Defensin 2 Regulation is Protective for Nontypeable Haemophilus Influenzae-Induced Middle Ear Infection. PloS One 9 (3), e90933. doi: 10.1371/journal.pone.0090933

Woo, C. H., Shin, S. G., Koh, S. H., and Lim, J. H. (2014). TBX21 Participates in Innate Immune Response by Regulating Toll-Like Receptor 2 Expression in Streptococcus Pneumoniae Infections. Mol. Oral. Microbiol. 29 (5), 233-243. doi: $10.1111 /$ omi.12061

Yang, D., Liu, Z. H., Tewary, P., Chen, Q., de la Rosa, G., and Oppenheim, J. J. (2007). Defensin Participation in Innate and Adaptive Immunity. Curr. Pharm. Des. 13 (30), 3131-3139. doi: 10.2174/138161207782110453

Yatsyshina, S., Mayanskiy, N., Shipulina, O., Kulichenko, T., Alyabieva, N., Katosova, L., et al (2016). Detection of Respiratory Pathogens in Pediatric Acute Otitis Media by PCR and Comparison of Findings in the Middle Ear and Nasopharynx. Diagn. Microbiol. Infect. Dis. 85 (1), 125-130. doi: 10.1016/ j.diagmicrobio.2016.02.010

Yonemura, S. (2011). Cadherin-Actin Interactions at Adherens Junctions. Curr. Opin. Cell Biol. 23 (5), 515-522. doi: 10.1016/j.ceb.2011.07.001

Zhang, X., Zheng, T., Sang, L., Apisa, L., Zhao, H., Fu, F., et al (2015). Otitis Media Induced by Peptidoglycan-Polysaccharide (PGPS) in TLR2-Deficient (Tlr2 $(-/-))$ Mice for Developing Drug Therapy. Infect. Genet. Evol. 35, 194-203. doi: 10.1016/j.meegid.2015.08.019

Conflict of Interest: The authors declare that the research was conducted in the absence of any commercial or financial relationships that could be construed as a potential conflict of interest.

Publisher's Note: All claims expressed in this article are solely those of the authors and do not necessarily represent those of their affiliated organizations, or those of the publisher, the editors and the reviewers. Any product that may be evaluated in this article, or claim that may be made by its manufacturer, is not guaranteed or endorsed by the publisher.

Copyright () 2021 Massa, Spann and Cripps. This is an open-access article distributed under the terms of the Creative Commons Attribution License (CC BY). The use, distribution or reproduction in other forums is permitted, provided the original author(s) and the copyright owner(s) are credited and that the original publication in this journal is cited, in accordance with accepted academic practice. No use, distribution or reproduction is permitted which does not comply with these terms. 